\title{
Architecture + Media
}

Digital Augmentations through Meta Media, Mappings, Real-time

Communication and Interactivity

Kishore M. Raheja, B.Arch (Hons.)

A Thesis submitted to the Department of Graduate Studies In Partial Completion of the Requirements for the Degree of

Master of Architecture (Professional)

Carleton University

Ottawa, Ontario

January 18, 2007 


$\begin{array}{ll}\begin{array}{l}\text { Library and } \\ \text { Archives Canada }\end{array} & \begin{array}{l}\text { Bibliothèque et } \\ \text { Archives Canada }\end{array} \\ \begin{array}{l}\text { Published Heritage } \\ \text { Branch }\end{array} & \begin{array}{l}\text { Direction du } \\ \text { Patrimoine de l'édition }\end{array} \\ \begin{array}{l}\text { 395 Wellington Street } \\ \text { Ottawa ON K1A ON4 }\end{array} & \begin{array}{l}\text { 395, rue Wellington } \\ \text { Ottawa ON K1A ON4 } \\ \text { Canada }\end{array}\end{array}$

Your file Votre référence ISBN: 978-0-494-23320-7 Our file Notre référence ISBN: 978-0-494-23320-7

NOTICE:

The author has granted a nonexclusive license allowing Library and Archives Canada to reproduce, publish, archive, preserve, conserve, communicate to the public by telecommunication or on the Internet, loan, distribute and sell theses worldwide, for commercial or noncommercial purposes, in microform, paper, electronic and/or any other formats.

The author retains copyright ownership and moral rights in this thesis. Neither the thesis nor substantial extracts from it may be printed or otherwise reproduced without the author's permission.
AVIS:

L'auteur a accordé une licence non exclusive permettant à la Bibliothèque et Archives Canada de reproduire, publier, archiver, sauvegarder, conserver, transmettre au public par télécommunication ou par l'Internet, prêter, distribuer et vendre des thèses partout dans le monde, à des fins commerciales ou autres, sur support microforme, papier, électronique et/ou autres formats.

L'auteur conserve la propriété du droit d'auteur et des droits moraux qui protège cette thèse. $\mathrm{Ni}$ la thèse ni des extraits substantiels de celle-ci ne doivent être imprimés ou autrement reproduits sans son autorisation.
In compliance with the Canadian

Privacy Act some supporting forms may have been removed from this thesis.

While these forms may be included in the document page count, their removal does not represent any loss of content from the thesis.
Conformément à la loi canadienne sur la protection de la vie privée, quelques formulaires secondaires ont été enlevés de cette thèse.

Bien que ces formulaires aient inclus dans la pagination, il n'y aura aucun contenu manquant.

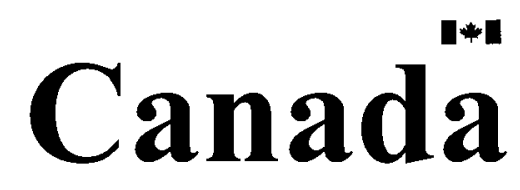




\begin{abstract}
This thesis is an architectural investigation of the process of translation of changing media in static physical space. It explores the changing relationship between dynamic media (real-time video, multimedia, meta media and internet) and static architecture in an effort to use the effects of these media to transform space. Chapter 1 gives an exhaustive analysis of the works of early media theorists such as Marshall McLuhan and Paul Virilio to present day media theorists such as Marcos Novak, Lev Manovich, Christina McPhee, Mirjam Struppek and Tore Slaatta in order to understand the blurred relation between media and architecture. Chapter 2 examines acoustic perception in media spaces through media theories demonstrated by architects such as Ole Bouman \& Kas Oosterhuis, UN Studio, Nox Architects, Greg Lynn, Zaha Hadid, Toyo Ito, Diller \& Scofidio and Weber \& Hofer in their projects by addressing the problematics of blurred media-space relations defined by the media theorists in Chapter 1 . Chapter 3 analyzes the problematics of design through representational means and acoustic perception. This chapter discusses how architects achieve changed perceptual experiences in their media projects through design processes using representational tools as well as through
\end{abstract}


the use of animation in digital environments. It also defines an alternate means of using representational tools (drawing and collage) as diagrams that organize physical space and translate the idea of animate experience through new media into built space by incorporating critiques of media and architectural theorists discussed in Chapters 1 and 2. Chapter 4 demonstrates these issues through the design of a media pavilion in a vibrant neighborhood called 'Adams Morgan' in Washington D.C. wherein interactive perceptual experiences are generated on the basis of the pavilion's physical-virtual program through a blending of space, multimedia, metamedia and real-time video media. 
To my wife and my parents for their

constant support and inspiration

iv 


\section{Acknowledgements}

1. Professor Thomas Mical, for his targeted guidance through all stages of the project

2. Professor Stephen Fai, for his continued support and guidance throughout the completion of this thesis.

3. Dr. Ben Gianni and Professor Masud Taj for their invaluable guidance for my project.

4. The staff of Martin Luther King Jr. Library, Washington, D.C. for providing me with historical land use plans of Adams Morgan area, Washington D.C. and reference materials on the Knickerbocker and Ambassador Theatres.

5. Chris Haust, DC Department of Planning, Washington, D.C. for providing me with present and proposed land use plans for the Adams Morgan area of Washington D.C. 


\section{TABLE OF CONTENTS}

List of Figures viii

List of Accompanying Materials xii

Introduction: Media Spaces - Architecture as Spectator 1

$\begin{array}{ll}\text { Media and Architecture } & 7\end{array}$

Figure/Ground Appositions \& Electronic Extensions $\quad 7$

$\begin{array}{ll}\text { Augmented Spaces } & 10\end{array}$

Augmentation through Surveillance $\quad 11$

Augmentation through Mappings and Meta-Media 12

Augmentation through Screens $\quad 24$

Acoustic Perception 33

$\begin{array}{ll}\text { Living Architecture } & 34\end{array}$

$\begin{array}{ll}\text { PhysicalNirtual Blending } & 37\end{array}$

Mappings through Objects and Fields $\quad 40$

Digital and Computational Architectures $\quad 43$

Spatial \& Conceptual Design Examinations in Digital Media 46

$\begin{array}{ll}\text { Augmented Architectures } & 49\end{array}$

Neural Architectures $\quad 52$

$\begin{array}{ll}\text { Urban Screen Facades } & 57\end{array}$

Towards the Design of New Media Architecture 60

Conceptual Design of New Media Architecture $\quad 64$

vi 
$\begin{array}{ll}\text { The Project } & 64\end{array}$

$\begin{array}{ll}\text { Design Challenge } & 64\end{array}$

Ideas to be Tested $\quad 64$

Design Strategy $\quad 65$

$\begin{array}{ll}\text { The Site } & 66\end{array}$

$\begin{array}{ll}\text { Design Program } & 68\end{array}$

Demonstrated Design Theories $\quad 77$

$\begin{array}{ll}\text { Conclusion } & 82\end{array}$

Design Drawings and Digital Models $\quad 88$

$\begin{array}{ll}\text { Bibliography } & 106\end{array}$

$\begin{array}{ll}\text { Appendix } 1 & 110\end{array}$

vii 


\section{List of Figures}

Fig. 1 Kas Oosterhuis \& Ole Bouman, Trans-Port (19982001). Hipercroquis Online Magazine. Oct. 202006. $<$ http://hipercroquis.wordpress.com/2006/10/05/transport-2001-kas-oosterhuis/>

Fig. 2 UN Studio, Real Space in Quick Times Pavilion, Milan Triennale (1996)

From: RealSpace in QuickTimes: EXPO. Netherlands Architecture Institute Online. 05 June 2006.

<http://www.nai.nl/wuw_riq/expo_images.html>

Fig. 3 Nox, Off-the-Road/103.8 Mhz, Blixembosch (1998) From: Kari, Jormakka. Flying Dutchmen: Motion in Architecture. Basel: Bikkhauser, 2002. 85-87.

Fig. 4 Greg Lynn, Port Authority Bus Terminal: Phase Portraits, Tubular beams from phase portrait vectors, Tensile fabric bands as screens for the projection of transportation information and surfaces for diffusion of light from below.

From: Basilisk Joumal Online. 15 July 2006.

<http://www.basilisk.com/P/portauthority_561.html>

Fig. 5 Zaha Hadid, Digital model of Rosenthal Center for Contemporary Art, Cincinnati, Ohio.

From: Rosenthal Center for Contemporary Art: Press Release. July 152006.

$<$ http://www.pritzkerprize.com/2004/pdf/ Rosenthal.pdf>

Fig. 6 Toyo Ito, Sendai Mediatheque, Sendai, Japan (2001) From: Galinsky Online.18 August 2006.

$<$ http://www.galinsky.com/buildings/

sendaimediatheque/index.htm> 
Fig. 7 Blur Building, Diller and Scofidio, Yverdon-Les-Bains, Switzerland (2002)

From: DesignBoom Magazine. 30 July 2006.

$<$ http://www.designboom.com/eng/funclub/

dillerscofidio.html>

Fig. 8 Weber \& Hofer, Lentos Museum of Modern Art in Linz, Austria (2003). Lentos Museum Home Page. 02 July 2006.

<http://mww.lentos.at/en/index.asp?nr=2>

Fig. 9 Land Use Plan, Adams Morgan, Washington D.C.

From: DC Department of Planning, Washington, D.C.

Fig. 10 Concept Diagram. Kishore Raheja, 01 Nov 2006

Fig. 11 Concept Diagram. Kishore Raheja, 01 Nov 2006

Fig. 12 Concept Diagram. Kishore Raheja, 01 Nov 2006

Fig. 13 Level 1 Floor Plan: Actors Spaces, Discotheque, Café, Exhibition Spaces and Chat stops. Kishore Raheja, 05 Nov 2006

Fig. 14 Level 2 Floor Plan: Theatre, workshops. Kishore Raheja, 05 Nov 2006

Fig. 15 Level 3 Terrace Level Plan. Kishore Raheja, 05 Nov 2006

Fig. 16 Level 4, 5 \& 6 Floor Plan: Artists Space, Multimedia Library \& Audiovisual Library. Kishore Raheja, 05 Nov 2006

Fig. 17 Level 7 Roof Plan. Kishore Raheja, 05 Nov 2006

Fig. 18 Sectional Elevation across Video Art Plaza, Exhibition and Workshops. Kishore Raheja, 07 Nov 2006 
Fig. 19 Sectional Elevation across theatre, discotheque, artists space, multimedia library and audiovisual library. Kishore Raheja, 05 Nov 2006

Fig. 20 Digital Architectural Model: Video Pavilion. Kishore Raheja, 15 Nov 2006

Fig. 21 Digital Architectural Model: Video Pavilion. Kishore Raheja, 15 Nov 2006

Fig. 22 Digital Architectural Model: Video Pavilion. Kishore Raheja, 15 Nov 2006

Fig. 23 Digital Architectural Model: Exhibit Space. Kishore Raheja, 17 Nov 2006

Fig. 24 Digital Architectural Model: Exhibit Space. Kishore Raheja, 17 Nov 2006

Fig. 25 Digital Architectural Model: Exhibit Space. Kishore Raheja, 17 Nov 2006

Fig. 26 Digital Architectural Model: Theatre. Kishore Raheja, 19 Nov 2006

Fig. 27 Digital Architectural Model: Theatre. Kishore Raheja, 19 Nov 2006

Fig. 28 Digital Architectural Model: Theatre. Kishore Raheja, 19 Nov 2006

Fig. 29 Digital Architectural Model: Chat Stop. Kishore Raheja, 21 Nov 2006

Fig. 30 Digital Architectural Model: Chat Stop. Kishore Raheja, 21 Nov 2006

Fig. 31 Digital Architectural Model: Chat Stop. Kishore Raheja, 21 Nov 2006 
Fig. 32 Digital Architectural Model: Foyer.

Kishore Raheja, 23 Nov 2006

Fig. 33 Digital Architectural Model: Foyer.

Kishore Raheja, 23 Nov 2006

Fig. 34 Digital Architectural Model: Foyer.

Kishore Raheja, 23 Nov 2006

Fig. 35 Digital Architectural Model: Cafetaria.

Kishore Raheja, 25 Nov 2006

Fig. 36 Digital Architectural Model: Cafetaria.

Kishore Raheja, 25 Nov 2006

Fig. 37 Digital Architectural Model: Cafetaria.

Kishore Raheja, 25 Nov 2006

Fig. 38 Digital Architectural Model: Discotheque.

Kishore Raheja, 27 Nov 2006

Fig. 39 Digital Architectural Model: Discotheque.

Kishore Raheja, 27 Nov 2006

Fig. 40 Digital Architectural Model: Elevations.

Kishore Raheja, 29 Nov 2006

Fig. 41 Digital Architectural Model: Elevations.

Kishore Raheja, 29 Nov 2006

Fig. 42 Digital Architectural Model: Elevations.

Kishore Raheja, 29 Nov 2006

Fig. 43 Digital Architectural Model: Elevations.

Kishore Raheja, 29 Nov 2006 


\section{List of Accompanying Materials:}

1. Site History

File Name:

History-Site.ppt

File Type:

Microsoft Powerpoint Presentation

File Size:

$9.45 \mathrm{MB}$

Medium:

Compact Disk

Medium Label:

Disk 1

2. Present Day Site Usage

File Name: PresentDay-Site.wmv

File Type: $\quad$ Video File (Windows Media Player)

File Size: $\quad 43.5 \mathrm{MB}$

Medium: $\quad$ Compact Disk

Medium Label: $\quad$ Disk 1

3. Design

File Name: Design.ppt

File Type: $\quad$ Powerpoint Presentation

File Size: $\quad 7.16 \mathrm{MB}$

Medium: $\quad$ Compact Disk

Medium Label: $\quad$ Disk 1

xii 


\section{INTRODUCTION: Media Spaces - Architecture as Spectator}

The present thesis is an architectural investigation of the process of translation of changing media (real-time video, multimedia, internet) and new media (meta-media) into static physical space. The changing relationships between media, new media, and architecture are explored in an effort to use the effects of these media to transform space.

If architecture is defined as the art of space, media, like music, is an art of time. In physics, spacetime is a mathematical model that combines space and time into a single construct called space-time continuum. This realization challenges the idea of separation between media and architecture and prompts the conception of a new "media architecture" as a space-time construct in which media and architecture come together.

Lev Manovich ${ }^{1}$ identifies new media's in its flexibility of not being anchored to any specific output.

\footnotetext{
${ }^{1}$ Lev Manovich is a Professor in the Visual Art Department, University of California, San Diego. He is the author of several texts that examine the impact of new media, telepresence, cinema, and virtual reality through media.
} 
"[c]omparing new media to print, photography or television will never tell us the whole story. For although from one point of view new media is indeed another type of media, from another it is simply a particular type of computer date, something stored in files and databases, retrieved and sorted, run through the algorithms and written to the output device... New media may look like media, but this is only the surface."

"If we want to describe what new media does to old media with a single term, "mapping" is a good candidate. Software allows us to remap old media objects into new structures turning media into 'meta-media'."

Electronic Media (multimedia, real-time media, video media, internet) and New Media (mappings and meta-media) are time bound artifacts created within their specific temporal contexts with the potential of instantaneous dynamic change. At the same time, these media generate changed perceptions due to dynamic physical and spatial relations connected across distances that cannot be completely experienced, but at the same time, are now accessible and habitable.

\footnotetext{
${ }^{2}$ Manovich, Lev. The Language of New Media . Cambridge, Mass.: MIT Press, 2001. 47-48.

${ }^{3}$ Manovich, Lev. Understanding Meta Media. 15 January 2006

$<$ <ww.ctheory.net/articles. aspx?id=493>
} 
According to Marcos Novak ${ }^{4}$, physical architecture has lost the potential to incorporate the dynamic changes in spatial qualities and experiences that are realized through digital technology and transmissible architectures.

"Time permeates every architectural gesture, but in most cases, architecture's concern with time is passive. Even where the idea of the time-image is employed in the evocative arrangement of elements intended to speak through implication, the elements and arrangement are static. $^{n 5}$

"In this effort to extend our range and presence to nonlocal realities, architecture has been a bystander, at most housing the equipment that enable us to extend our presence. ${ }^{n 6}$

Architecture changes through time as well. However, this change is implied over the life of a building. Therefore, the time scales of change between media and architecture are different. In relation to media, the temporal change in architecture is insignificant, and architecture is rendered as utilitarian. Nevertheless, the rate of temporal change in architecture is highly significant with respect to

\footnotetext{
${ }^{4}$ Marcos Novak is an architect, artist, composer, and theorist investigating actual, virtual and mutant intelligent environments. He originated the study of liquid architectures in cyberspace, and is founding director of the RealityLab and the Advanced Design Research Program, School of Architecture, University of Texas at Austin.

${ }^{5}$ Novak, Marcos. Transmitting Architecture: The Transphysical City. 12 Feb. 2006. <www.ctheory.net/articles.aspx?id=76>

${ }^{6}$ Refer Footnote 5
} 
the human body which is in no hurry to travel at the speed approaching that of light, whence the effect of the space-time continuum are experienced. Furthermore, Novak suggests that architectural design processes using representational tools such as drawings and models (manual and CADD) can no longer transform space.

"Architectural heuretics and poetics, even when employing the computer's boundary representations and solid modeling, still emphasize a Euclidean understanding of form and space. Descriptively, analytically, synthetically, in every way, the rigidity of the canonical, orthographic descriptions of architecture fail to capture what is salient to space as we currently conceive it."

Based on the above, several issues can be raised. First, how do media and architecture come together so that changing media is translated into physical space? Second, how does this dynamic experiential change translate from idea/concept to a built space, and lastly, how does media continue to transform physical space after the space has been built? Media theorists have explained the relation between media and architecture as "blurred" through concepts such as "electronic extensions" and "acoustic space" (Marshall McLuhan), "surveillance" (Paul Virilio), "digital data

\footnotetext{
${ }^{7}$ Refer Footnote 5
} 
translation" (Marcos Novak), "augmentation", "meta-media" and "screens" (Lev Manovich), "continuum" (Christina McPhee), and "performative interfaces" (Mirjam Struppek and Tore Slaatta) ${ }^{8}$. An exhaustive analysis of the works of early media theorists clearly identifies these concepts and serves as a basis for the subsequent criticism. Criteria of the successful design of new media architecture are defined on the basis of this analysis.

At the same time, architects have successfully examined the relation between media and architecture through their theoretical interpretations in projects such as Trans-Port Pavilion (Kas Oosterhuis \& Ole Bouman), RealSpace in QuickTimes Pavilion (UN Studio), Off the Road/103.8 MHz (NOX Architects), Port Authority Bus Terminal (Greg Lynn), Rosenthal Center for Contemporary Art (Zaha Hadid), Sendai Mediatheque (Toyo Ito), Blur Building (Diller \& Scofidio), and Lentos Museum of Art (Weber \& Hofer). ${ }^{9}$

In order to analyze this media-space relation, the following criteria are examined:

\footnotetext{
${ }^{8}$ Please refer to Chapter 1 "Media and Architecture" for definitions of mediaspace concepts and more information about the media theorists stated hereinabove.

${ }^{9}$ Please refer to Chapter 2 "Acoustic Perception" for a description and analysis of the media-space architectural projects stated above and for more information about the corresponding architects.
} 
a. What is the method of investigation of the design?

b. How does media/new media transform the architecture during the design process?

c. How does media/new media transform built architecture?

Different modes of design investigation and translation (drawings, modeling, CADD, digital computerization of environmental forces) used by the media-space architects are analyzed to examine whether they allow for the translation of media into the built space. These analyses are used to examine how an alternate method of design of media spaces can be achieved from the translation of animate experience through media and new media into built space using representational tools.

This alternate design method is used to demonstrate the theoretical issues through the design of a Media Pavilion in a vibrant neighborhood called 'Adams Morgan' in Washington D.C. wherein changing interactive perceptual experiences are generated in the built space on the basis of the pavilion's physical-virtual program through a blending of space, multimedia, metamedia and real-time video media. The next stage of design development is discussed. 


\section{MEDIA AND ARCHITECTURE}

Figure/Ground Appositions and Electronic Extensions:

"The medium is the message.."10

According to McLuhan ${ }^{11}$, media spaces are combinations of visual and acoustic space structures in which linear architectural spaces (Visual structures/ground) accommodate electronic media (acoustic structures/figure). McLuhan proposed that media themselves, not the content they carry, should be the focus of study. McLuhan's theory was that a medium transforms the ground in which it plays a role by the characteristics of the medium itself.

Media that is assimilated in an experience can be called "figure". The "ground", or environment, is not a passive container, but an active process that influences the relationships between all of the elements in it. In the electronic age, this implies the creation of a new architectural environment that is not a "passive wrapping" but an "active process" environment that takes into account the

\footnotetext{
${ }^{10}$ McLuhan, Marshall. Understanding Media: The Extensions of Man. New York: McGraw-Hill, 1964. p. 20

${ }^{11}$ Marshall McLuhan was a Canadian educator, philosopher, and scholar. A professor of English literature, a literary critic, and communications theorist, McLuhan's work is viewed as one of the cornerstones of the study of media ecology.
} 
apposition of both figure and ground instead of concentrating solely

on an abstract sequence or movement isolated from any ground.

"All media extensions are extension of some human faculty psychic or physical. Electric circuitry, an extension of the nervous system, Media by altering the environment, evoke in us unique ratios of sense perceptions. The extension of any one sense alters the way we think and act - the way we perceive the world."12

McLuhan states that electronic media are changing our lives.

Media is the extension of some human faculty and, at the same time, it works as environment in which humans are submerged like fish in water. Changes in media change users of the environment. Electronic media allows involvement and mythic depth.

According to Felix Stalder ${ }^{13}$, McLuhan's figure/ground (content/medium) concept is the approach of perceptual organization in gestalt ${ }^{14}$ perception toward the reality generated

\footnotetext{
${ }^{12}$ McLuhan, Marshall. Understanding Media: The Extensions of Man. New York: McGraw-Hill, 1964. 34.

${ }^{13}$ Felix Stalder is a researcher and activists in the field of social implications of ICTS. He teaches media economy at the Academy of Art and Design, Zurich; is a co-founder of Openflows.org, an open source R\&D firm headquartered in Toronto. He is currently one of the moderators of nettime mailing list(nettime-l)

${ }^{14}$ Gestalt as a psychological modality was first developed in western laboratories as an approach similar to Skinnerism with a focus on basic perception such as
} 
through media and media effects. McLuhan defines ground very poorly; basically as that which is ignored. While this has the advantage of not being trapped in inadequate categories, in the context of formulating a strategy for the design of media spaces, this is problematic, as it does not specifically define the nature of the built space as ground/medium ${ }^{15}$.

Architectural spaces combined with new media technologies of communication, telecommunication, information, and interactions have the potential to extend the physical, virtual, and psychic domains of its users. Therefore, this incorporation of media in architecture directs changed perceptions of space and experiences by the nature and type of media that is incorporated within.

"The medium is the massage." ${ }^{16}$

\footnotetext{
sight, taste, touch and the cognitive process: how the human mind/body translates and responds to contact with everyday life situations.

${ }^{15}$ Stalder, Felix. "From Figure / Ground to Actor-Networks: McLuhan and Latour". Paper given at the Many Dimensions: The Extensions of Marshall McLuhan Conference, Toronto, 23-25 October 1998.

${ }^{16}$ McLuhan, Marshall. The Medium is the Massage: An Inventory of Effects. New York: Bantam Books, 1967. p. 14
} 
"The medium is the massage" implies that the experience of the body is primary to the experience of media and new media effects in a media space. It is through the body that media and architecture come together in a media space.

\section{Augmented Spaces}

Manovich defines "augmented space" as "physical space" filled with "electronic and visual information".

"While physical space was always augmented by images, graphics and type; but substituting all these by electronic displays makes possible to present dynamic images, to mix images, graphics and type and to change the content at any time."1

In his article 'The Poetics of Augmented Spaces: Learning from

Prada,' Manovich discusses augmentation through "video

surveillance technologies" and through "publicly located

computer/video displays". In his article "Understanding Meta

\footnotetext{
${ }^{17}$ Manovich, Lev. The Poetics of Augmented Space: Learning from Prada. 09 June $2006<\mathrm{http} / / / \mathrm{www}$.manovich.net/DOCS/augmented_space.doc>
} 
Media $^{18}$, Manovich discusses the concepts of "mapping" and "meta-media". In his article 'Behind the Screen: Russian New Media', Manovich discusses the importance of the "screen as a bridge between physical and virtual spaces".

In this section, these methods are analyzed through the theoretical writings of Paul Virilio, Marcos Novak, Christina McPhee, Alan Liu, Tanaka Jun, Tajima Noriyuki, Tore Slaatta and Mirjam Struppek as:

a. Augmentation through Surveillance

b. Augmentation through Mappings and Meta Media

c. Augmentation through Screens

\section{a. Augmentation through Surveillance}

"The montage of unmanned lenses of automatic surveillance cameras; the complete absence of visual subjectivity into an ambient technical effect, a sort of permanent pan cinema which, unbeknown to us, turns our most ordinary acts into movie action." 20

\footnotetext{
${ }^{18}$ Manovich, Lev. Understanding Meta Media. 15 January 2006 $<w w w$.ctheory.net/articles. aspx?id=493>

${ }^{19}$ Manovich, Lev. Behind the Scene: Russian New Media. 15 January 2006 $<w w w . c t h e o r y$. net/articles. aspx?id=93>

${ }^{20}$ Virilio, Paul. The Vision Machine. Bloomington : Indiana University Press, 1994.
} 
Paul Virilio ${ }^{21}$ examines changes in technology to study the changes in the way we perceive. According to Virilio, the use of video imaging machines in legal and police representation gave birth to a new form of "hyper-realism" that makes it possible to do away with the body of a person and replaces it with a "real-time telepresence" through "substitution". Virilio predicted surveillance saturation as an absorption of urban topographies and architectures into pure vision created by the machine for the machine through technologies of representation.

According to Manovich, "video surveillance technologies" used to transmit and connect streaming video through telecommunication and the internet now make it possible to have shared real-time experience and are now available everywhere. At the same time, "publicly located computer / video displays" present this visible information to passers by connecting the processes of surveillance with shared experience through large flexible displays (screens) and interactive connectivity.

\footnotetext{
${ }^{21}$ Paul Virilio is a renowned urbanist, political theorist and critic of the art of technology. Born in Paris in 1932, Virilio is best known for his 'war model' of the growth of the modern city and the evolution of human society. He is also the inventor of the term 'dromology' or the logic of speed.
} 
"Still, a first impulse of artistic practice within a culture of digital terror is to break up the space, to smash it open, to revive it by using surveillance technique as a generative medium for a human centered aesthetic. Like an archaeological dig through debris of anesthesia and amnesia - the culture of forgetting - the smashed ruins of a panoptic city may be a new ground, even an unimaginable agora saturated with conversation and energy, contretemps, against time. Building reiterative experiential archives, tracing terrains, and integrating recursive polyphonic spatial imaging with in live space creates a dynamic and critical subjective presence, a conscious architecture."22

According to Christina McPhee ${ }^{23}$, surveillance techniques can act as generative media that can be used to create a dynamic presence and a conscious architecture. When surveillance technologies are transformed into portals of communication, their mediation into an architectural space will lead to changed experiences of space within the new media architecture.

Virilio's critique of surveillance spaces as visions created by/for the machine and hyper-realism is problematic as both Manovich and McPhee discuss the potential of using surveillance technologies to generate new experiences. Manovich's stand on the use of

\footnotetext{
${ }^{22}$ McPhee, Christina. Net Baroque. 20 January 2006 $<w w w$.ctheory.net/articles. .aspx? id $=399>$

${ }^{23}$ Christina McPhee, a transmedia artist, lives in California. She works in painting, drawing, sound art, and performance cinema installation, most recently at the San Francisco Performance Cinema Symposium (September 2003).
} 
surveillance techniques to generate shared real-time and broadcast experience through streaming telecommunication media is relevant to the design of media spaces as it allows for multiple experiences to be (re) created within a space, and at the same time, allows for this experience to be shared across similar physical and virtual networks and pavilions.

McPhee's examination of the "human centered aesthetic" is relevant as it highlights the importance of media transformations and experiences in relation to the body to generate dynamic experiences in a "conscious architecture" and establishes changing "grounds" through surveillance. Therefore, the relation between media and architecture engages the subjective body, which, through surveillance, experiences dynamic transformations of media as a changing and transmissible spatial construct. Augmentation through surveillance becomes an important criterion for the design of media space as it allows for multiple, real-time, joint and changing experiences in relation to the body and transforms the space into a dynamic, conscious architecture that broadcasts real-time events and experiences to similar physical and virtual spaces. 


\section{b. Augmentation through Mappings and Meta-media}

"If we want to describe what new media does to old media with a single term, "mapping" is a good candidate. Software allows us to remap old media objects into new structures turning media into "meta-media."

According to Manovich, meta-media acquire three new properties:

a. The translation of data from one domain into another (Time into 2d space, 2d into $3 d$ space, image into $3 d$ space, etc.)

b. Media objects can be manipulated using Graphical User Interfaces (GUI)

c. Media objects can be processed using standard techniques of computerized data processing: search, sort, replace, etc.

These properties of meta-media allow for a generation of design processes in which architecture is transformed through translation of data. New media becomes a generator of new spaces and experiences during the design process. The architect sets the criteria for the transformations but does not necessarily control the output of these transformations. At the same time, given the static

\footnotetext{
${ }^{24}$ Manovich, Lev. Understanding Meta Media. 15 January 2006 $<w w w . c t h e o r y . n e t / a r t i c l e s . a s p x ? i d=493>$
} 
nature of built space, these transformations can be applied during the design process and not after the physical execution of the space. When media and new media are digitally incorporated into the physical built space, the dynamic changes in meta-media transform physical space instantly and generate changing experiences for the body within the media space.

Therefore, the changes in media space are a result of dynamically transforming media and meta-media that instantaneously change experiences of the body within the space. The space remains static in physical proportions; the experience is dynamic and changing. Like spaces augmented through surveillance, these changes can be broadcast to similar physical and virtual pavilions thereby extending the experience of the body, or allowing the body to engage with external, transmitted, experiences.

"An alternative architectural poetics would look past the static depiction of objects and surfaces to the description of latent information fields." ${ }^{25}$

\footnotetext{
${ }^{25}$ Novak, Marcos. Transmitting Architecture: The Transphysical City. 12 February 2006. <www.ctheory.net/articles.aspx?id=76>
} 
Novak $^{26}$ suggests environmental and force field mappings through computerization as a generator of new media spaces. The resulting media spaces have the potential to act as active environmental processes and therefore, will lead to new experiences and changed perceptions of space. Novak's use of latent force fields as mappings is, in Manovich's terms, a meta-mediatic transformation of space. This process is applicable to the design process as an animate experience of space in which media continually transforms physical space. The next stage of transformations of the structure of this space can be realized only as virtual space. Physical space cannot move and change after it is built in the manner that dynamic changes in the environment transform it in the virtual domain.

Novak's critique of architecture as static space is valid in terms of spaces designed to accommodate programmatic arrangements of space as well as digital computational spaces generated through meta-mediatic process, as the built space will not transform any further once the digital transformations realized through computational processes are built.

\footnotetext{
${ }^{26}$ Marcos Novak is an architect, artist, composer, and theorist investigating actual, virtual and mutant intelligent environments. He originated the study of liquid architectures in cyberspace.
} 
"There are those like Marcos Novak who claim that design is free in cyber architecture because there is no gravity, but this is just a kind of utopian idea of architecture as having escaped the limitations of the human body.... Freedom in architecture can be realized through media as simple as drawings.... if you look at the kind of designs that have come out of cyber architecture so far, they have tended to fall back into a kind of rigid, expressionistic formalism. This kind of tendency has been directly discussed through the metaphor of fluid architecture-but representing information spaces through this kind of impossible, a(na)morphous distorted space has deep ideological significance. We are being fooled into thinking that this world is more glamorous and fascinating than plain old reality. ${ }^{27}$

Tanaka and Tajima ${ }^{28}$ critique Novak's approach towards free design in cyber architecture as "rigid, expressionistic formalism", which, while "glamorous", is not very different from traditional design techniques. Because physical spaces, built from these new media transformations, do not change after being built, these spaces become rigid, expressionist formal interventions. The dynamism of media does not transform space once the project is

${ }^{27}$ Jun, Tanaka and Tajima Noriyuki. "Cyberspace and the City/Architecture/The Body". Intercommunication, No.24, Spring, 1998. 15 July 2006. < http://www.ntticc.or.jp/pub/ic_mag/ic024/074-083e.pdf>

${ }^{28}$ Tanaka Jun is Associate Professor in the Department of Interdisciplinary Cultural Studies of the Graduate School of Arts and Sciences, University of Tokyo. His writings include, Architecture in the Afterimages: At the 'End' of Modernism, Miraisha, and Studies in Modernism (coauthored) Shichosha. Tajima Noriyuki, Architect, founded the TATA architectural firm together with TADA Yasushi after graduation from the AA School in 1993. In 1994 he founded YAPPU, an organization using Macintosh equipment to conduct international multimedia activities in planning, graphic design, music, and architecture. 
built. Therefore, Manovich's meta-media transformations of physical space through the incorporation of media technologies within built space are a more valid approach toward the development of dynamic changing experiences within media spaces.

\begin{abstract}
"Among his other projects, Novak programs fourdimensional, algorithmic architectural shapes that mutate in time, then extracts from the unimaginable four-dimensional matrix three- or two-dimensional snapshots (through 3D rapid prototyping or 2D imaging). The result is a reduceddimension data pour from a higher-dimensional reality designed to elicit what Novak terms allogenetic, truly alien aesthetics beyond the ken even of neoromantic notions of transcendence. Yet what instinct compels Novak to materialize and form his unimaginable $4 D$ shapes in $3 D$ or $2 \mathrm{D}$ at all? Why is that stepping down of the dimensional plenum necessary?
\end{abstract}

Moreover, what criteria motivated this specific presentation of the unimaginable out of all the algorithmic possibilities? Why choose this image as especially interesting?.... When the material substrate was removed to allow for Internet transmission, that is, variable methods of standardizationfor example, XML documents governed by a common standard but adaptable to undetermined kinds of hardware, software, and usages - could suddenly be imagined. Material embodiment-in the substrate of a work and the bodily practices of the artisanal artist both-was now immaterial to the full, independent expression of content and form. Is the writer or artist any longer an author in such circumstances, let alone a creative one?" ${ }^{29}$

\footnotetext{
${ }^{29}$ Liu, Alan. "Transcendental Data: Toward a Cultural History and Aesthetics of the New Encoded Discourse." Critical Inquiry. 20 July 2006.

<http://criticalinquiry.uchicago.edu/features/artsstatements/arts.liu.htm>
} 
Alan $\mathrm{Liu}^{30}$ critiques the role of the designer in computational architectures such as those proposed by Novak. According to Liu, the use of algorithmic processes is suspect as only those processes that yield new forms are being embraced. In the absence of definite criteria, the designer does not actually author the forms and spaces generated and is, therefore, no longer responsible for the creative output.

Therefore, this digital and computational blended translation of media into space is deprived of authorship and responsibility. It does not engage the body in this translation and becomes a formal gesture that does not transform architectural space after the space is built. This calls for alternate design processes that do not necessarily depend on computational transformations of space through the blending with environmental forces and latent fields.

\footnotetext{
${ }^{30}$ Alan Liu is a Professor in the English Department at the University of California, Santa Barbara, where he has taught since 1988. He received his Ph.D. from Stanford University in 1980 and taught in the English Department and British Studies Program at Yale University from 1979-87. His central interests include British Romantic literature and art, information culture, new media, literary theory, and cultural studies.
} 
"One formal continuum in relational aesthetics moves from film into architecture by spatialization of time based media within built volumes. Another conceptualizes topologies in architecture as musical/mathematical recursive structure. A third wants the built volume to remember, as a trace of kinesthetic human memory, the touch of remembrance of things past. An interactive space in virtual construction is cyberpresent at the confluence of at least these three functions." ${ }^{31}$

According to Christina McPhee ${ }^{32}$, interactive media spaces come together as a continuum through spatialization of time-based media, musical/mathematical mappings, and history. She has illustrated this blending through her net art projects and several writings on interactive virtual art spaces. In the physical design of media spaces, the realization of "musical/mathematical structures" is another transformation through meta-media. Therefore, as discussed previously, these transformations of space are independent of computer-based digital architectures as they remain formal gestures and do not transform further after the physical space has been built.

\footnotetext{
${ }^{31}$ McPhee, Christina. Net Baroque. 20 January 2006 $<w w$.ctheory.net/articles. aspx? id $=399>$

${ }^{32}$ Christina McPhee, a transmedia artist, lives in California. She works in painting, drawing, sound art, and performance cinema installation, most recently at the San Francisco Performance Cinema Symposium (September 2003).
} 
However, the blending of these mappings with physical space becomes possible through digital technologies incorporated into physical space in a manner that physical space is constantly transformed and the body experiences changing spaces through meta-media generated in this space. The history of a site/place/event, when mapped, projected or displayed onto the architectural space recreates past remembrances within this new media space, which can, simultaneously, disappear to integrate, for example new musical structures and meta-media.

"Imagine interpolated virtual and actual spaces thrive and decay, die and live in a riparian zone, watered by pervasive computing. How can we set in motion a generative theory around a drama of the sense of place that derives from the mixed reality of the virtual and the actual?... Might the condition of nomadic paralysis in media space, as frightening as it may feel, be the precursors of a new poetics of (an)architecture, where space, smashed between cyber and physical, shifts into a hyperbolic super-present?"33

New media spaces that interchange virtual, real-time, and actual spaces through computing have the potential to change the perception and the experience of those spaces through changing programs and interactions within an architectural space. This strategy can generate new forms of "electronic extensions" that

\footnotetext{
${ }^{33}$ Refer Footnote 31
} 
appear and subsequently transform into portals of information, experience, effects, or into physical space. Changing time, events, and media elements that form part of this architecture lead to a real-time changing experience of the present. These computational techniques and physical-virtual blending mapped onto architectural spaces can generate new media and spatial experiences and are therefore desirable.

The augmentation of physical space through mappings of history, media and meta-media that blend physical and virtual spaces by digital technological incorporation of new media in physical space generate dynamic experiences for the body through changing events and transformations of media space. Meta-media that act as generators of time-based spaces through digital computation do not translate the dynamic transformations of media into built physical space and, at the same time, run the risk of becoming formal expressions deprived of specific design criteria and authorship of the designer.

Therefore, the process of transforming new media into space does not necessarily involve time-based digital computerization 
techniques, as these methods do not transform physical space after it is built like they do in the virtual domain. The spatialization of time-based media can be a meta-media mapping within a physical space that transforms the experience of the user. The history of a place and events can be incorporated into physical media space as interactive representations through media technologies built into a physical space. A blending of physical and virtual space generates a new media experience/event in a space and allows for the transmission of new forms of interaction and joined experience through the Internet.

\section{c. Augmentation through Screens}

"Will we soon replace the ensemble of apartment furniture with the active and dynamic vectors that will themselves progressively but radically modify the configuration of the building, and then the architectural morphology? (...) Having made the window autonomous through the television screen, and the door through the automobile, will we now participate in the complete disintegration of the building? ${ }^{\text {n34 }}$

Virilio asked the question whether the basic dimensions for space and time were being lost in the process of replacement of interiors

\footnotetext{
${ }^{34}$ Virlio, Paul. Lost Dimension. First published in French in 1984. New York: Semiotext(e), 1994
} 
and furniture with mobile telecomputer furniture and electronic matrix screens of pixels and artificial light. New media technology seemed to destabilize the senses and make people move as mobile nomads in a space without dimensions. Virilio's question is now extended to include the exterior and the urban space as well. As he foresaw, it seems that the landscape of urban buildings is being replaced with active and dynamic media technologies that radically modify the configuration of the city and the urban morphology. Buildings, urban landscapes, and sites are disintegrating to become autonomous, informational, and transitional objects. As Armand Mattelard ${ }^{35}$ once put it, the paradoxes of modern communication are "...tumult rhymes with secret, overdose with scarcity, and transparency with opacity." ${ }^{136}$ According to Virilio's more hyperbolic interpretation, we are losing the human capacity for seeing and understanding from a certain perspective.

"...The pixel replaces the bolt and rivet. The eye of the telespectator slides along the length of an infinite electronic perspective, and the architecture of light becomes nothing more than the computer's memory - a sequential, modular or matrix system that was prefigurated by the first metallic

\footnotetext{
${ }^{35}$ Armand Matellart is Professor of Information Sciences and Communication and Head of the department at the University of Upper Brittany.

${ }^{36}$ Mattelart, Armand. Advertising International. The Privatization of Public Space. London: Routledge, 1991. 86.
} 
structures, the optic theaters and other panoramas of the nineteenth century." ${ }^{\text {"37 }}$

According to Struppek ${ }^{38}$, digital display infrastructure that appears

in the modern urban landscape renders public space as a

moderator and a communication medium. The current dominantly

commercial use of screens can be extended to display cultural

content and these screens can become a tool to contribute to a

lively urban society if they involve their audience interactively.

\begin{abstract}
"Urban Screens combines the function of public space for commerce and trade with a cultural role reflecting the wellbeing of urban society: digital moving displays with a new focus on supporting the idea of urban space as a space for the creation and exchange of culture and the formation of a public sphere using criticism and reflection. Their digital nature makes these "screening platforms" an experimental visualization zone on the threshold of virtual and urban public space." 39
\end{abstract}

\footnotetext{
${ }^{37}$ Virilio, Paul. Lost Dimension. New York: Semiotext(e), 1994. 81.

${ }^{38}$ Mirjam Struppek works as urbanist, researcher and consultant in Berlin. She has lectured and published essays with a special focus on the livability of urban space, public sphere and its transformation and acquisition through new media. Since $\mathbf{2 0 0 2}$ she is developing the online-information-platform interactionfield.de about the relation of interaction, new media and public space.

${ }^{39}$ Struppek, Mirjam. "The Social Potential of Urban Screens". Screens and the Social Landscape. Sage Publications, Volume 5, No.2, 2006. 173-188.
} 
Urban screens have the potential to form a new integrated digital layer of the city that redefines the growing function of digital infrastructure. The ability of these screens to display of cultural content and to contribute to the exchange of information within a lively urban society would integrate them more into the communal context of the space and therefore help create local identity. Harmonizing the content, location, and type of screens would determine the success of interacting with the audience.

Urban screens have the potential to generate local orientation and identification through joint experiences of news, cultural events, concerts, film screenings, and sports events. The connection of screens with cultural centers and institutions producing and preserving digital content as video art reach a new audience of passers-by, thus bringing cultural content into outdoor public spaces. The consideration of the locality and site-specificity of urban screens, both in shape and content, helps connections in the perception of urban space.

The production of cultural content that is displayed on urban screens now lies in the hands of every passer-by through cellular 
phones in the form of sms and mms messaging, image capture, and video that can be instantly transmitted to the urban screen. Interactive screens embedded in urban furniture can help circulate and access data for comments, stories, and conversations that establish communication within the local community.

The emergence of Internet culture has brought new ways for participation and exchange that challenges hierarchical authorship. Connections of the urban screen with the Internet and digital experiments in online worlds bring the culture of collaborative content production and networking to a wider audience for inspiration and engagement.

"It seems that the urban space has become an experimental stage for all kinds of screen technologies, ranging from advertisement boards, decorative facades, information boards, live video screening, traffic signalling, stage backdrops and virtual landscapes, to experimental digital architecture using screens and illuminating or illuminated glass and transparent plastics as building materials. The wide ranging technological possibilities are presently pursued in hybrid combinational ideas for reconfiguring private and public spaces and visual forms into a performative architecture within a virtual, digitalised urban visual culture. ${ }^{, 40}$

\footnotetext{
${ }^{40}$ Slaatta, Tore. "Urban Screens: Towards the convergence of Architecture and Audiovisual Media". First Monday, Special Issue \#4: Urban Screens: Discovering the Potential of Outdoor Screens for Urban Society. 15 April 2006. <http://www.firstmonday.org/issues/special11_2/slaatta/\#author>
} 
Tore Slaatta ${ }^{41}$ discusses recent strategies used to combine architecture with media that lead to a new genre of performative architecture in the digitalised urban environment through screen technology. These techniques indicate changes in the architectural experience through changes in the quality and content of the urban screens and interfaces that make up new mediated architectural spaces. These spaces blended with digital interactive urban screens can, therefore, generate a new media experience of "transitory", "transformational", and "informative" architecture.

\begin{abstract}
"The screen media technology can (more or less) in one moment be made to disappear. And in the next moment it can stand out, seek for connections; ask for your involvement and interactivity. The screen thus does not resemble earlier media technologies that had to have a separate physical carrier (the television set, the radio, the telephone). Instead, it can disappear, become a wall, become a window, hide as modern architecture, or fake another building's facades. The urban screen imitates nature, and it is the mediated visual, the technologically produced and distributed image that stands out or melts into the environment. Media becomes landscape. The screen can potentially become invisible by imitating or reflecting its surroundings. ${ }^{42}$
\end{abstract}

\footnotetext{
${ }^{41}$ Tore Slaatta is Professor at Department of Media and Communication at the University of Osio. He writes on issues related to European cultural policies, urban development, design, architecture and art criticism and has worked as a consultant and board member in the Norwegian design industry.

${ }^{42}$ Refer Footnote 40
} 
The interactive nature of the technologically mediated screen makes it possible to generate new experiences of space through interactivity. Representational architectural techniques and design methodologies will also lead to changing experiences of architecture as this perception of the architecture is always changing through the media that is incorporated on the screen. Manovich ${ }^{43}$ discusses the screen as a bridge between physical and virtual space, analog and digital space, and as a unification of media and new media.

"For Russian thinkers, the meaning of the screen expands far beyond its function as a surface displaying an image originating from elsewhere: it is also a bridge across two spaces, one physical, one imaginary; a link between a human subject and an audio-visual stream; and a rectangular window which opens onto alternative (virtual) reality. So understood, the "screen" is that which unites old and new media, still and moving image, analog and digital culture." 44

Therefore, the augmentation of media space through screen technology allows for the augmentation of space through

\footnotetext{
${ }^{43}$ Lev Manovich is a Professor in the Visual Art Department, University of California, San Diego. He is the author of several texts that examine the impact of new media, telepresence, cinema, and virtual reality through media.

44 Manovich, Lev. Behind the Scene: Russian New Media. 15 January 2006 $<w w w$. ctheory. net/articles. aspx?id=93>
} 
surveillance as video display, the augmentation through mapping and meta-media as well as the augmentation through a blending of physical and virtual spaces using the interactive screen. In highlighting the connection between screen and architecture in a media space, Manovich quotes,

'Going beyond the 'surface as electronic screen paradigm', architects now have the opportunity to think of the material architecture that most usually preoccupies them and the new immaterial architecture of information flows within the physical structure as a whole. In short, I suggest that the design of electronically augmented space can be approached as an architectural problem. In other words, architects along with artists can take the next logical step to consider the 'invisible' space of electronic data flows as substance rather than just as void - something that needs a structure, a politics, and a poetics. ${ }^{n 45}$

Virilio critiqued urban screens stating that our basic dimensions of space and time were displayed through active and dynamic media technology in urban spaces in a manner that human senses can no longer understand these technological changes to the city fabric where buildings are replaced by screens. According to Struppek, these screens display cultural content, are interactive, blend

\footnotetext{
${ }^{45}$ Manovich, Lev. The Poetics of Augmented Space: Leaming from Prada. 9 June 2006. <http://uww.manovich.net/DOCS/augmented_space.doc>
} 
physical and virtual spaces, and the production of images and video content displayed on these screens lies with the users through their cellular phones. For Slaatta, the wide ranging technological possibilities of media space through screen technologies presently pursued reconfigure private and public spaces as well as transform visual forms into a performative architecture within a virtual, digitalised, urban visual culture. Manovich, who discusses public video displays as an augmentation technique for media spaces, has, through his research on Russian new media artists, expressed the screen as a bridge between physical and virtual space, analog and digital cultures, image and video. In his recent works, he discusses electronic augmented spaces as architectural problems that should be reconfigured by architects in collaboration with artists to generate new media spaces. Therefore, the augmentation of media space through screen technology is not a disintegration of physical space, but is, in fact, a re-appropriation of the architectural façade that transforms with user-input content and interactive content.

This augmentation generates a blend between physical and virtual space, as also analog and digital space, and at the same time, 
converts the façade into a transitory architecture of performance, interaction, and information. The blending of physical and virtual spaces, history and meta-media on the urban screen will therefore lead to changing events and experiences for the body within media spaces. The screen becomes an important medium for the representation of video media, multimedia, and meta-media in a media space.

\section{ACOUSTIC PERCEPTION}

In the present section, I have analyzed the design methods of architects who have successfully examined the relation between media and architecture through their theoretical interpretations in projects such as Trans-Port Pavilion (Kas Oosterhuis \& Ole Bouman), RealSpace in QuickTimes Pavilion (UN Studio), Off the Road/103.8 MHz (NOX Architects), Port Authority Bus Terminal (Greg Lynn), Rosenthal Center for Contemporary Art (Zaha Hadid), Sendai Mediatheque (Toyo Ito), Blur Building (Diller \& Scofidio), and Lentos Museum of Art (Weber \& Hofer). ${ }^{46}$

\footnotetext{
${ }^{46}$ Please refer to Chapter 2 "Acoustic Perception" for a description and analysis of the media-space architectural projects stated above and for more information about the corresponding architects.
} 


\section{Living Architecture}
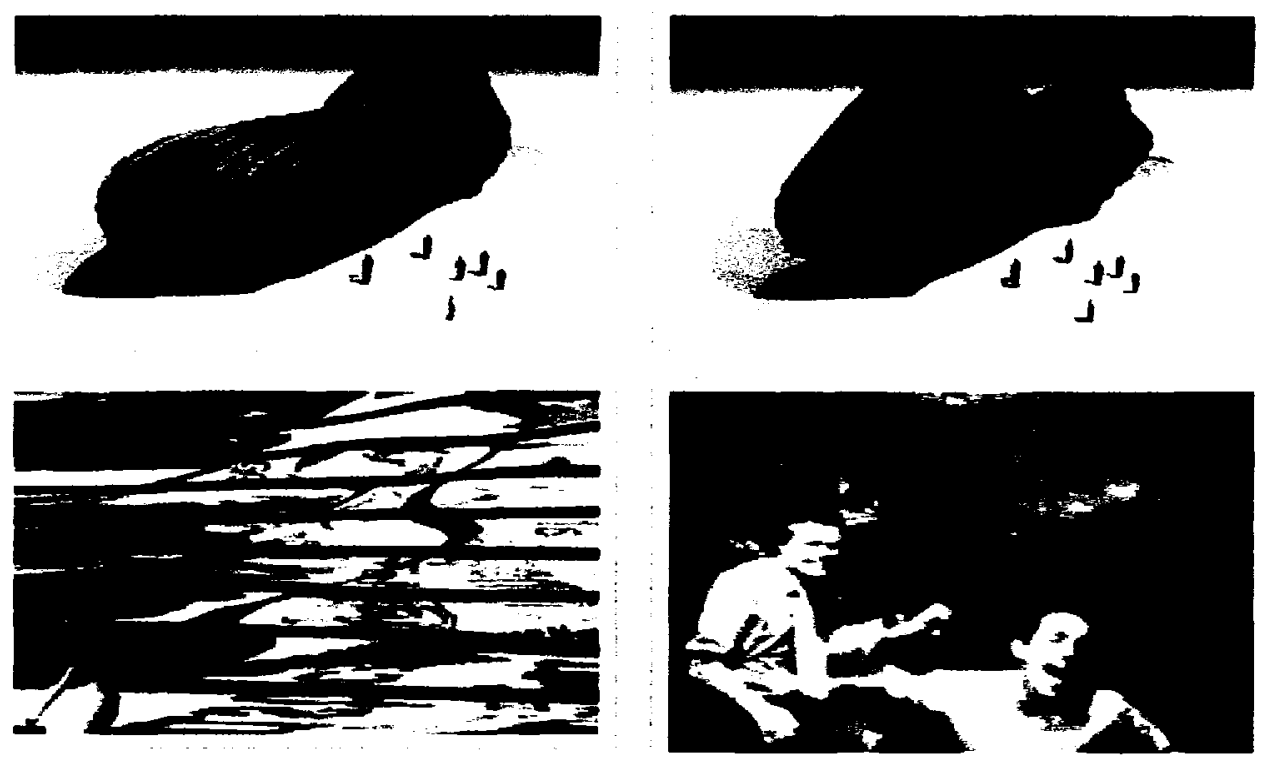

Fig. 1 Kas Oosterhuis \& Ole Bouman, Trans-Port Pavilion ${ }^{47}$, Venice, 2001

The Trans-Port pavilion forms part of a network of real and virtual pavilions on the Internet. This multifunctional pavilion can be rented for use as a virtual interpretation center on the Internet, a meeting place, a disco, and a television studio. Its active structure changes physical shape through data representing external forces from the Internet and physical visitors through pneumatic muscles controlled by structural engineering software. Its interior skin is a mobile giant virtual window to global information sources like websites and

\footnotetext{
${ }^{47}$ From: Hipercroquis Online Magazine. 20 October 2006.

< http://hipercroquis.wordpress.com/2006/10/05/trans-port-2001-kas-oosterhuis/>
} 
webcams. It operates in several modes: art, office, network, information, commercial and dance modes; and immerses its users.

Method of Investigation:

This project is designed to materialize the ideas of the architects through representational methods of design using sketches, drawings and CADD to translate the idea into built form.

Transformation through media and new media during design:

Media does not transform the architecture in any manner during the design process. It only allows for an examination of structural possibilities of changes in shape of the pavilion on the basis of the criteria that the architects have programmed.

Transformation through media and new media after execution: As a built space, this project demonstrates how the augmentation of physical space through surveillance transforms space when these data fields are transmitted through the Internet to similar spaces that they augment as video displays. At the same time, this 
project demonstrates how multimedia, real-time media, and blendings of the physical and the virtual transform space and the user experience of this space through the augmentation of its interior walls by screens.

Critique of the Project:

The project moves and changes shapes according to the needs of the users. However, this remains problematic because the building still maintains its form, demarcates inside/outside and figure/ground relations as the transformations of the screen remain an interior experience and do not translate to the exterior of the pavilion. This project illustrates how representational design techniques such as drawings, sketches, and CADD enable the translation of the architect's concepts of media space into a built space. The subsequent augmentation of this built space through video displays, screens, multimedia, and video generate changing experiences for the users of this space. The transmission of experiences joined within this space and the interaction of users with the architectural interface enhances this changing relation. 


\section{Physical/Virtual Blending}

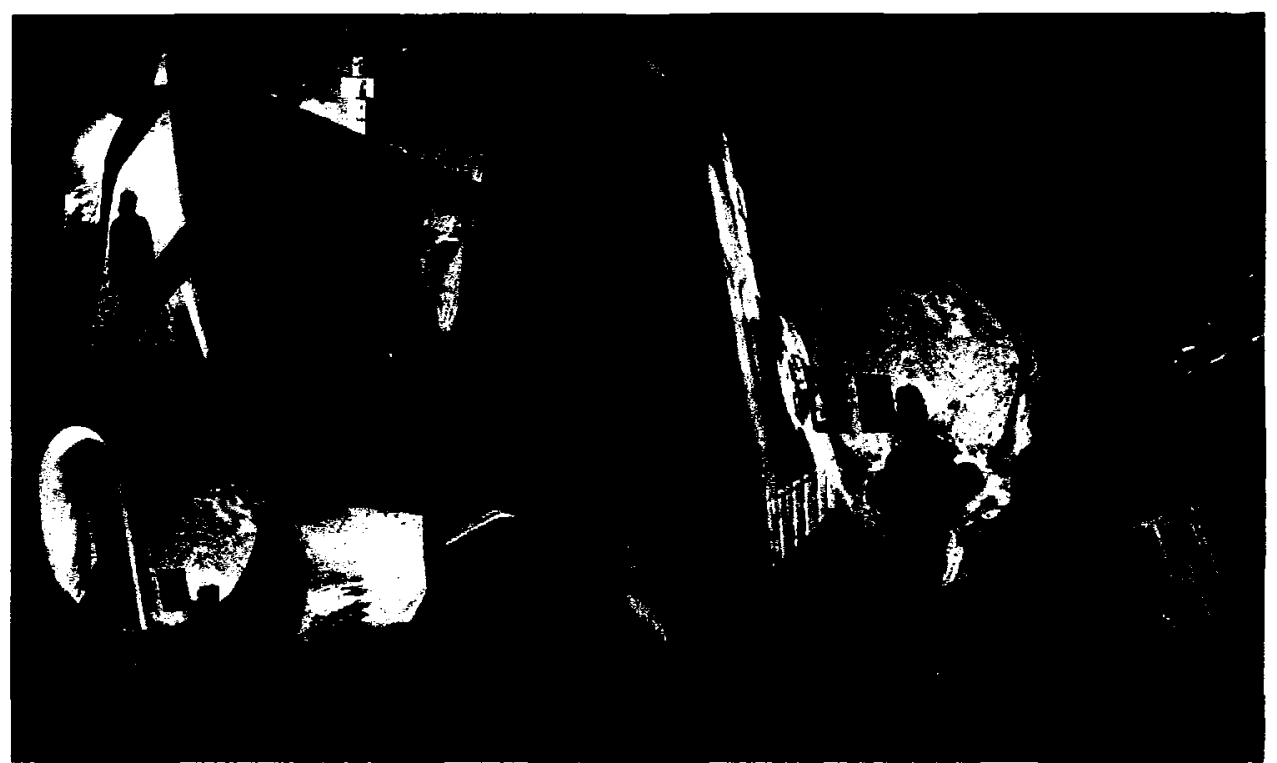

Fig. 2 UN Studio, RealSpace in QuickTimes Pavilion, Pavilion Bienale di Milano, Milan, $1996 .{ }^{48}$

"The RealSpace in QuickTimes pavilion acts as a sculptural framework for an exhibition of multiple moving images. It provides a space that corresponds, within the given technical, organizational and financial limits, to the promises of electrotecture. At the same time it is intended as a documentary: in a series of films it shows us what effect the rise of the computer is having on the world around us.

The pavilion is not only about new digital spaces, it is itself a space, and the public's experience of this space is of prime importance. To underscore this point, the pavilion contains a promenade architecturale. Starting out as a physical experience, at a certain point it switches to virtual mode where further progress involves mouse clicking or mindzapping. This is no mere entertainment; it is also intended to provoke critical reflection on the quality of the lifeworld in a digital age. The exhibition is actually a series of

\footnotetext{
${ }^{48}$ From: RealSpace in QuickTimes: EXPO. Netherlands Architecture Institute Online. 05 June 2006. <http://www.nai.nl/www_riq/expo_images.html>
} 
questions - posed in 3D and 4D - about the cultural reasons and spatial implications of the digital revolution." ${ }^{.49}$

Method of Investigation:

The curving shapes of the pavilion's walls are the transformation of the designer's ideas achieved through representational tools such as drawing and CADD.

Transformation through media and new media during design:

Media and New Media do not transform the space at the design stage and translate the designer's ideas into built space.

Transformation through media and new media after execution:

The project demonstates how augmentations of physical space by multimedia and Internet technologies transform the space. A blending of physical and virtual spaces essential for the progression along the pavilion generates changed experiences in the built space. Multimedia transforms the experience of this space as a venue for performance and interactivity.

${ }^{49}$ Ben Van Berkel and Caroline Bos. RealSpace in QuickTimes: EXPO. Netherlands Architecture Institute Online. 05 June 2006.

<http://www.nai.nl/www_riq/expo_images.html> 
Critique of the Project:

This project incorporates Manovich's concept of media augmentation in physical space. The blending of figure/ground and inside/outside relations clearly demonstrates McLuhan's concept of linear/visual spaces. McPhee's theory of continuum within architecture is demonstrated through the blending of physical and virtual spaces that interchange within the pavilion. Slaatta \& Struppek's concepts of performative and interactive screens are also established through the interactive projections connected to multimedia and Internet content in this pavilion.

This project illustrates how acoustical media spaces can be generated from a concept. The digital design medium is used to transfer the idea of the architect into a built interactive media experience. The tools of representation used to transfer a concept into built space generate spaces with changed perception and new interactive experiences through the dynamic transformation of the content that constitutes the inside/outside spaces of this pavilion. The changing experiences of the user are the result of changing content that the user generates with his/her input. 


\section{Mappings through Objects and Fields}

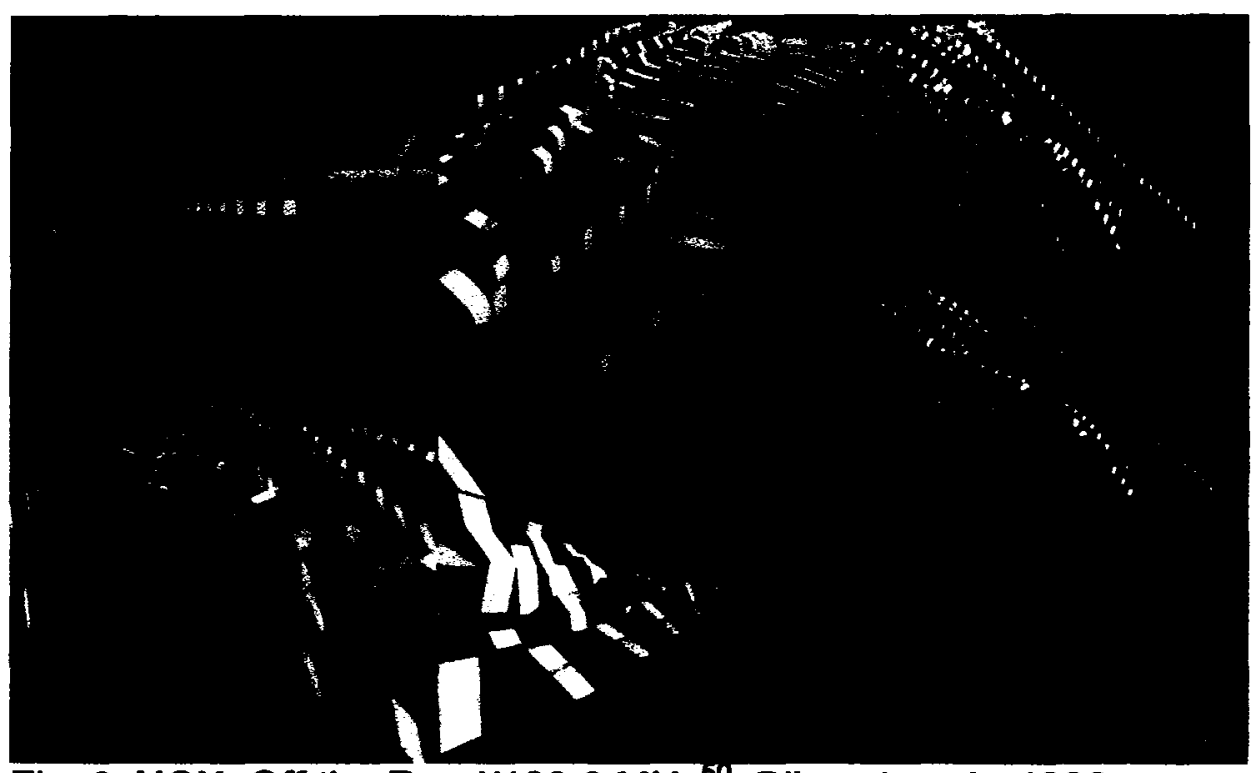

Fig. 3 NOX, Off the Road/103.8 MHz ${ }^{50}$, Blixembosch, 1998.

"If architecture is conceived as the dynamic product of interacting fields of forces, it is not only the distinction between the body and the building which dissolves, but also the distinction between inside and outside. Instead of designing objects with a spectacular inside but no connection to exterior systems, one needs to consider the ways the building taps into other fields of forces that area all in motion and have no clear spatial boundaries." ${ }^{51}$

\section{A large-scale project by NOX Architects ${ }^{52}$ for the Blixembosch}

\footnotetext{
${ }^{50}$ From: Kari, Jormakka. Flying Dutchmen: Motion in Architecture. Basel: Bikkhauser, 2002. 85-87.

${ }^{51}$ Hypersurface Architecture II. London: Thames \& Hudson, 2000. 26.

52

NOX is the architecture office in Notterdam of the internationally acclaimed innovator Lars Spuybroek. Lars Spuybroek is at the forefront of the international debate of the usage of new media in architecture. Since the early nineties he has been involved in the researching the relationship between architecture and media, and between architecture and computing.
} 
district in Eindhoven portrays thinking about an architectural problem in terms of a field. The architects arranged 208 houses in a regular grid, which was then inflected in response to noise level, as affected by the topography and interference patterns between the houses. The shapes of individual houses are deformed according to the three-dimensional inflection of noise in order to transform sound into a new real-time sound mapping composition that is broadcast back to the environment through computing at 103.8 $\mathrm{MHz}$ so drivers can tune their car radios to a fluid sonic landscape.

Method of Investigation:

The design employs the digital design environment to examine transformations of objects in space.

Transformation through media and new media during design:

Digital computational techniques allow for the mapping of sound levels on houses and enable the development of the planning scheme as well as the virtual shapes of the houses as a metamedia transformations of sound that are translated into built spaces. 
Transformation through media and new media after execution:

Digital computational techniques allow for a collection of sound levels reflected from the houses by passing cars; a new sound mapping composition is remixed through computational techniques. A new real-time composition (meta-media) is broadcast to drivers of the cars through their radios.

Critique of the Project:

While the meta-mediatic transformation of space through sound fields created by passing cars transforms the shapes of houses and the layout planning of houses in the design stage, this transformation does not carry forward after the houses are built. The residents do not experience any changes in the perception of their built space. This project generates changing experiences only for drivers of cars driving through the sonic landscape. This project demonstrates that meta-mediatic transformations of digital space have the potential to transform physical space but do not translate further once the space is built. The next stage of transformations of physical space through meta-media involves a qualitative transformation of content housed within this space. 


\section{Digital and Computational Architectures}

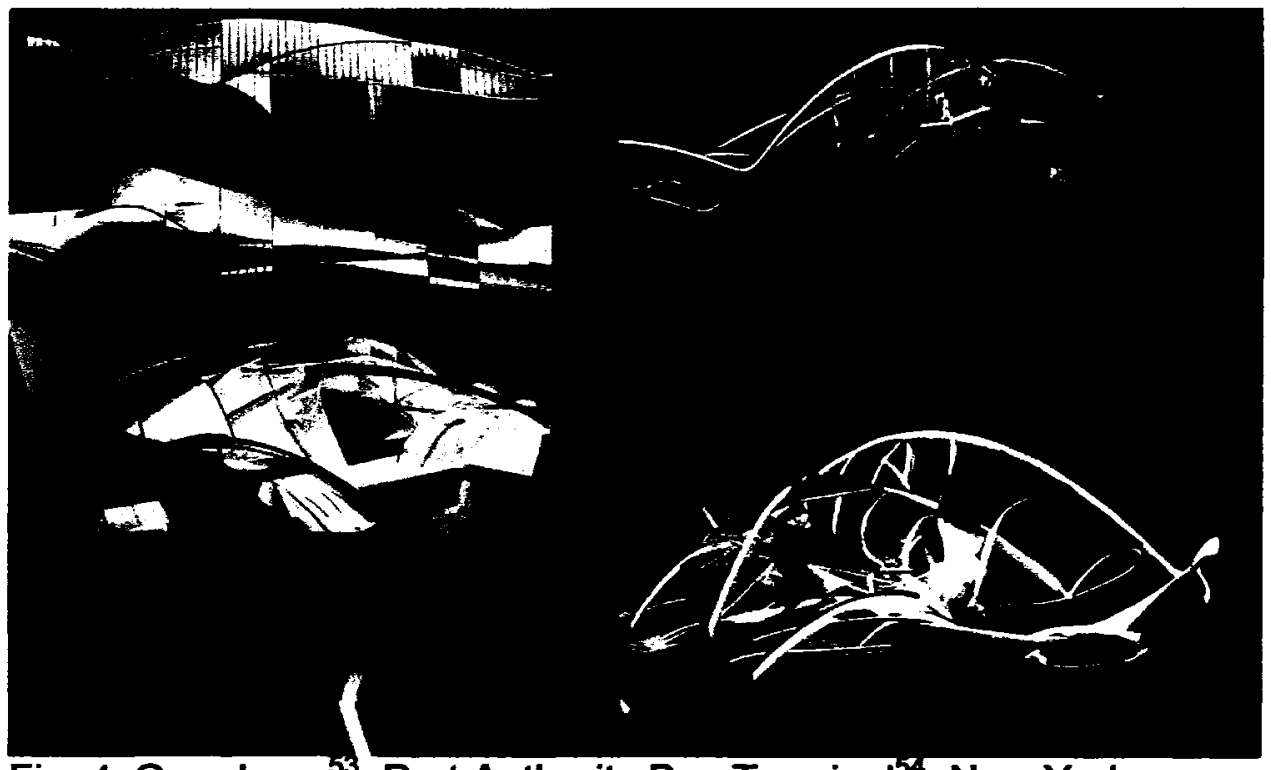

Fig. 4 Greg Lynn ${ }^{53}$, Port Authority Bus Terminal ${ }^{54}$, New York, Competition, 1995.

"In contrast, animate design is defined by the co-presence of motion and force at the moment of formal conception.

Instead of a neutral abstract space for design, the context for design becomes an active abstract space that directs form within a current of forces that can be stored as information in the shape of the form. Rather than as a frame through which time and space pass, architecture can be modeled as a participant immersed within dynamical flows."

53

Greg Lynn (born 1964), graduated cum laude from Miami University $(\mathrm{OH})$ with degrees in Architecture and Philosophy, and Princeton University with a Master's of Architecture, is an American architect, philosopher, and science-fiction writer who advocates increased used of computer-aided design to produce irregular, biomorphic architectural forms.

${ }^{54}$ From: Basilisk Journal Online. 15 July 2006.

<http://www.basilisk.com/P/portauthority_561.html>

${ }^{55}$ Lynn, Greg. Animate Form. New York, N.Y: Princeton Architectural Press, 1997. 11. 
Lynn's proposal for the Port Authority Gateway competition involved the design of a protective roof andlighting scheme for the underside of bus ramps leading into Port Authority Bus Terminal, New York.

Method of Investigation:

The site was modeled in the digital design environment using forces that simulate the movement and flow of pedestrians, cars, and buses across the site, each with different speeds and intensities of movement, and the four elevated bus ramps emerging from below the Hudson River.

Transformation through media and new media during design:

To discover the shape of the invisible gradient field of attraction across the site generated by the various forces of movement, Lynn introduced geometric particles that change their position and shape according to the influence of the forces. From the particle studies, he captured a series of phase portraits of the movement cycles over a period of time. These phase portraits are swept with a secondary structure of tubular frames linking ramps, existing buildings, and Port Authority Bus Terminal. 
Transformation through media and new media after execution:

Eleven tensile surfaces are stretched across the tubular frames as an enclosure and projection surface. However, new media incorporated in the built space does not transform the space or the user's experience of this space in any manner.

Critique of the Project:

The incorporation of media on the tensile fabric bands is a mere assignment of function to the end similar to generic media augmentation in physical spaces. Also, Lynn's design process is problematic as it absolves the architect from the responsibility of authorship for computational processes that exclude the viewer due to the absence of scale, site, or other points of reference.

This project also demonstrates the limitations of meta-mediatic transformations of space through digital computational techniques that do not further transform built space. Changing spatial experiences are generated by housed media technologies. 


\section{Spatial \& Conceptual Design Examinations in Digital Media}

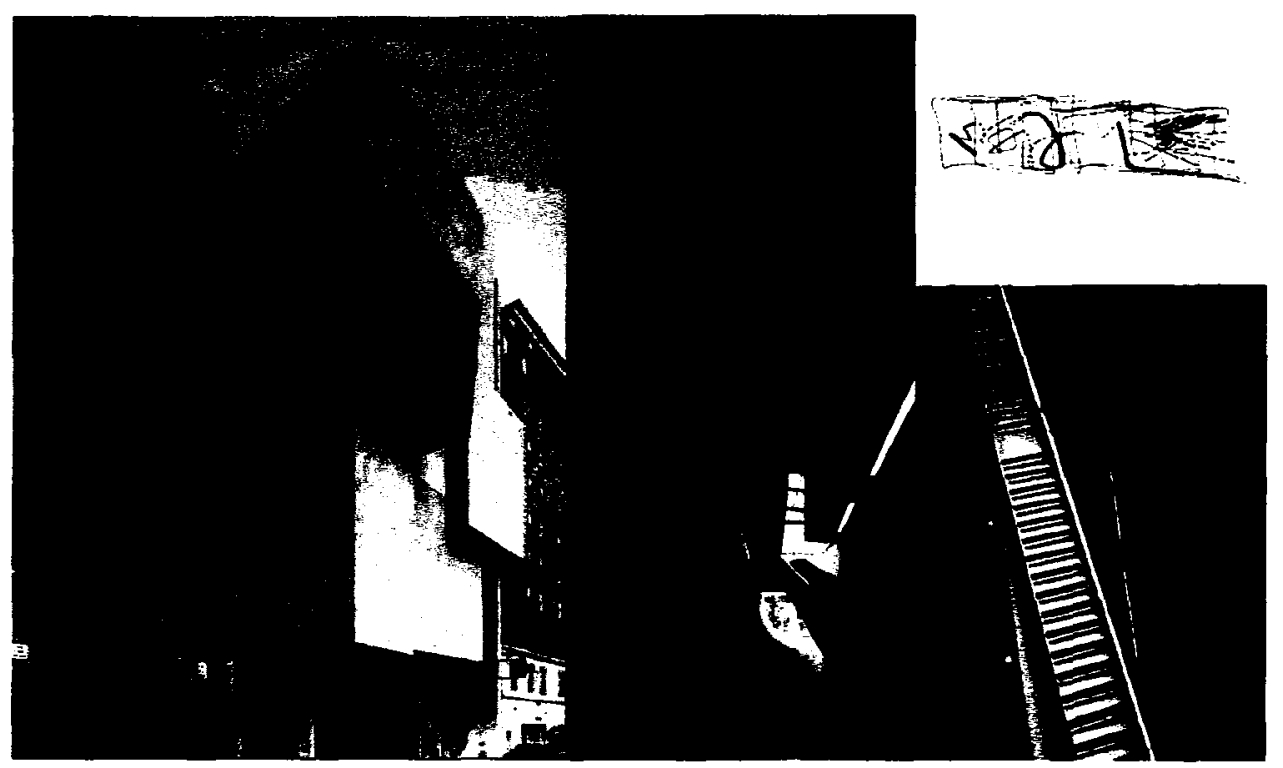

Fig. 5 Zaha Hadid, Rosenthal Center for Contemporary $\mathrm{Art}^{56}$, Cincinnati, Ohio, 2003.

"A sense of movement will be sweeping into the building from the square...you move your body on a journey though the building...The ground curves slowly upward as it enters the building, rising to become the back wall. As it rises and turns, this 'Urban Carpet' leads visitors up a suspended mezzanine ramp through the full length of the lobby, which during the day functions as an open, day-lit, 'landscape' expanse that reads as an artificial park. ...The galleries are expressed as if they had been carved from a single block of concrete and were floating over the lobby space. Exhibition spaces vary in size and shape, to accommodate the great range of scales and materials in contemporary art. Views into the gallery in the circulation system are unpredictable as the stair ramp zig-zags upward through a narrow slit at the back of the building."57

\footnotetext{
${ }^{56}$ From: Rosenthal Center for Contemporary Art: Press Release. 15 July 2006. <http://www.pritzkerprize.com/2004/pdf/Rosenthal.pdf>

${ }^{57}$ From: Hadid, Zaha. Contemporary Arts Center Page, 2003. ArcSpace Online Magazine. 15 June 2006. <www.arcspace.com/architects/hadid/ contemporary_arts_center/ contemporary_arts_center_index.htm>
} 
Method of Investigation:

Hadid uses a series of sketches, physical models, and computer models as representational tools to translate her ideas of animate experience.

Transformation through media and new media during design: There is no transformation of space through media and new media during the design stage. In the design process for the CAC, Hadid uses computer modeling in conjunction with analog media for the communication of concept and spatial condition to transform her ideas about an animate experience rather than to generate form/experience.

An animation that accompanied her competition entry reveals the conceptual transformation of an 'Urban Carpet' that curls into place, aligning the remaining forms into the recognizable arrangement of the façade, the viewer comes to understand the animated composition of the building. 
Transformation through media and new media after execution:

There is no transformation of the built space through media or new media interventions.

Critique of the Project:

Hadid's images illustrate a translation from conceptual language to a language of construction; the animation reinforces this translation, revealing the connection between the two. Because Hadid's animation comes near the end of the design process, it does not explore a mobile virtual experience as the influencing factor in the generation of the architecture. Even so, the effectiveness of Hadid's translation from a concept to a built form is a precedent that should be aspired to when considering the realization of a digitally represented experience. Hadid's approach illustrates that representational techniques such as sketches, drawings, models and CADD models translate the ideas of animate experience through the realization of the architect's concepts. New Media transformations can be applied to built spaces to generate changing experiences of space and interactions within this performative space through media augmentations. 


\section{Augmented Architectures}

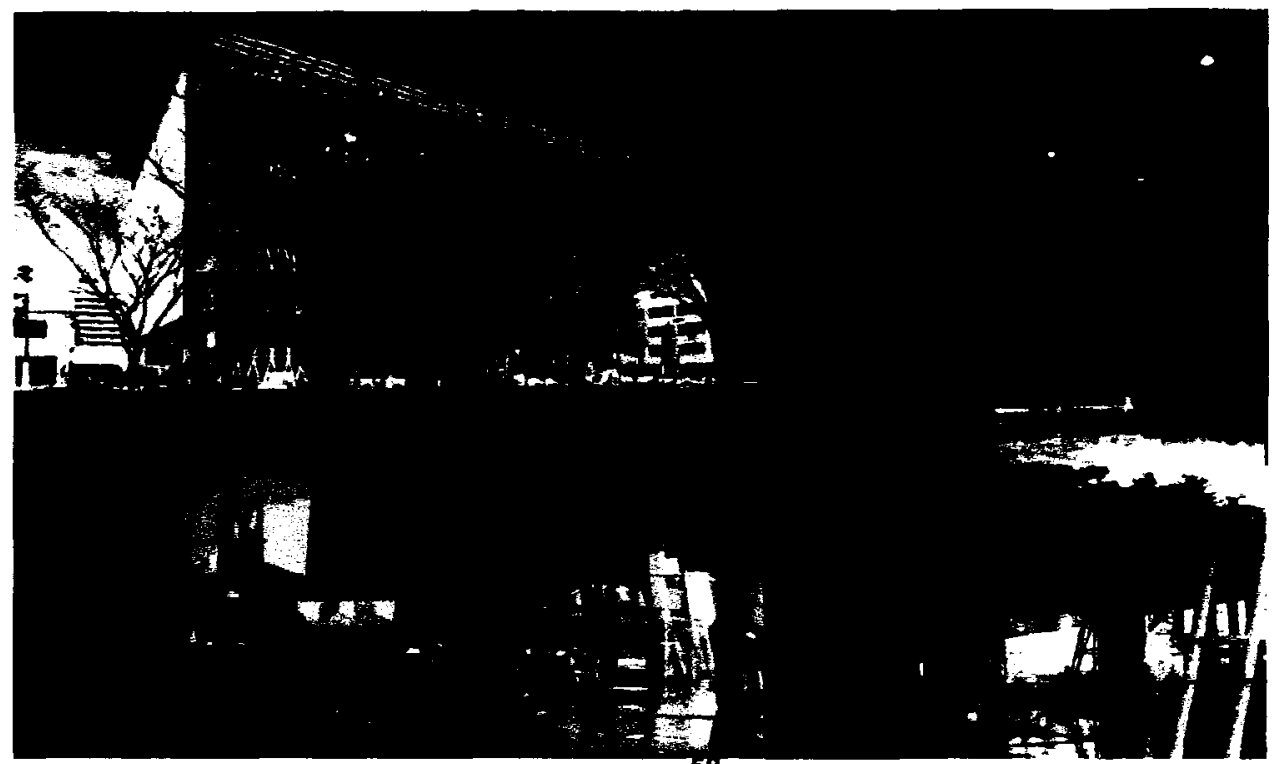

Fig. 6 Toyo Ito, Sendai Mediatheque ${ }^{56}$, Sendai, Japan, 1995

"Originally inspired by the image of floating seaweed, Toyo Ito's multi-purpose cultural center, the Sendai Mediatheque, is a structure both transparent and light. Thirteen steel tubular lattice structures penetrate the design and carry the weight of the 15.75 inch thin floor slabs on each of seven floors, giving the building the impression of being suspended in mid-air. Light is central to the Mediatheque's appearance: when not flooded by daylight, the structure glows artificially from within. Located in Sendai, Japan, the Mediatheque houses a library, art gallery, audio-visual library, film studio, and café, and was the subject of an architectural competition in which Ito's was the winning entry. ${ }^{.59}$

\footnotetext{
${ }^{58}$ From: Galinsky Online

$<$ http://www.galinsky.com/buildings/sendaimediatheque/index.htm

Barrie, Andrew. Media Architecture $<>$ Architectural Media. Artspace Future

Magazine. 18 June 2006. <http://uww.artspace.org.nz/shows/lto.htm>

${ }^{59}$ Ito, Toyo, Albert Ferre \& Tomoko Sakamoto. Toyo Ito: Sendai Mediatheque.

Spain: Actar, 2002.
} 
Sendai Mediatheque is a center for activities in the fields of art and film, serving as a public facility to help people exchange information freely with each other through various media and learn how to use that information.

Method of Investigation:

The project employs representational techniques such as sketches, drawings, and computer models to translate the architect's ideas of blending structure, light, and program into a built space.

Transformation through media and new media during design: Media do not play a role in transforming architectural space in the design process. Media, however, play a role in the organization of space and program through the proximity of programmed spaces to light wells that act as structural systems for the pavilion.

Transformation through media and new media after execution: In this project, media and new media do not generate changed experiences in the built space. Media technologies such as video, 
Internet, and multimedia transform the spatial organization and lead to new combinations of interactive space.

Critique of the Project:

This project demonstrates how blending of structure, light, and program that is augmented with technologies of communication and interaction through mobile interior screens generates new media spaces from a concept. The architect's concept and authorship is primary to the generation of a new media experience.

The project illustrates how changed perceptions within a media space result from the architect's vision for this space that is independent of digital design environments, mappings, metamedia, or interpolations between virtual and physical spaces. While the project still exhibits the McLuhan's concept of visual space structure through figure/ground implications, the transparency of the facades that reveal activities within the Mediatheque and the interior mappings of real-time communication and the Internet technologies blur the relation between inside and outside, real and virtual. 


\section{Neural Architectures}

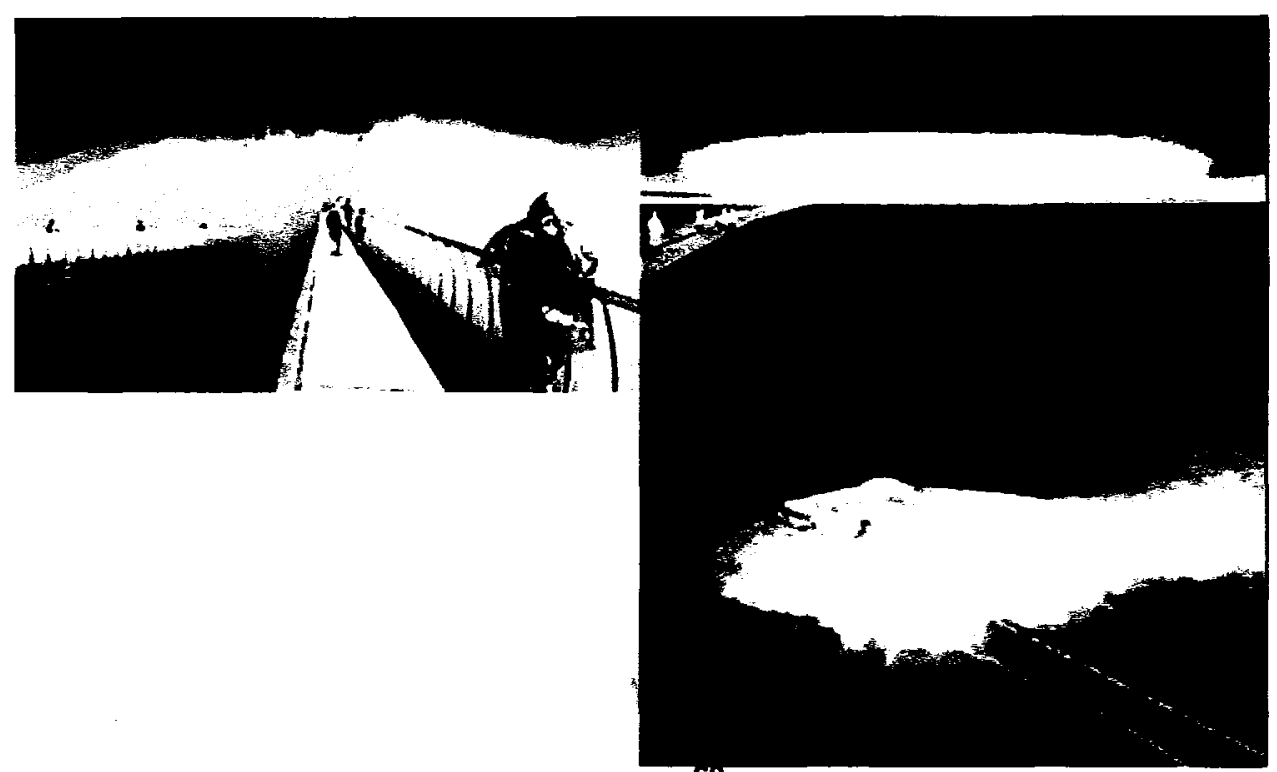

Fig. 7 Diller \& Scofidio, Blur Building ${ }^{60}$, Yverdon-les-Bains, Switzerland, 2002

"The Blur Building is a media pavilion for Swiss Expo 2002 situated at the base of Lake Neuchatel in Yverdon-les-Bains, Switzerland. The pavilion is made of filtered lake water shot as a fine mist through 13,000 fog nozzles creating an artificial cloud. A built-in weather station controls fog output in response to shifting climatic conditions such as temperature, humidity, wind direction, and wind speed. The public can approach Blur via a ramped bridge that deposits visitors at the center of the fog mass onto a large open-air platform where movement is unregulated. Visual and acoustical references are erased along the journey toward the fog leaving only an optical "white-out" and the "whitenoise" of pulsing water nozzles.

Prior to entering the cloud, each visitor responds to a questionnaire or character profile and receives a "braincoat" (smart raincoat). The coat is used as protection from the wet

${ }^{60}$ From: "Blur Building." DesignBoom Magazine. 25 June 2006.

<http://uww.designboom.com/eng/funclub/dillerscofidio.html> 
environment and storage of the personality data for communication with the cloud's computer network. Using tracking and location technologies, each visitor's position can be identified and his or her character profiles compared to any other visitor. As visitors pass one another, their coats will compare profiles and change color indicating the degree of attraction or repulsion among $\mathbf{4 0 0}$ visitors at any time.

The final ascent to the Angel Bar resembles the sensation of flight as one pierces through the cloud layer to the open sky. Here, visitors relax, take in the view, and choose from a large selection of commercial waters, municipal waters from world capitals, and glacial waters. At night, the fog will function as a dynamic and thick video screen." 61

Method of Investigation:

The project employs representational tools like drawings and computer models to translate the architect's vision of changing perceptions and interactions through digital computerization and artificial intelligence within the pavilion.

Transformation through media and new media during design:

Media does not transform architectural space during the design process. Computer media assist in the construction of the pavilion.

\footnotetext{
${ }^{61}$ Scofidio, Ricardo. Home Page. Cooper Union School of Architecture. 20 July 2006. <uww.cooper.edu/architecture/faculty/faculty/scofidio/scofidio04.html>
} 
Transformation through media and new media after execution:

The architecture is by design an interactive space that uses

computerization, sensors, and artificial intelligence to generate new

environmental effects, interactions, and changing experiences.

Critique of the Project:

According to Brian Massumi ${ }^{62}$,

"the human brain coordinates events -- neuronal firings -that interact in complex ways. These events are triggered by changes in the environment, and what comes out of their interaction are movements of our body in the environment, oriented to the changes. Change is the fundamental force of experience. So instead of being a machine for transmitting images, the brain is a machine for translating, or transducing, the force of change into oriented movement. The pattern of the movement is an evolving, emergent form of being. Or rather, of becoming -- because the shape of our lives changes as a result. The brain itself also changes. It has a plasticity, which means that its network of neural connections is itself always evolving. ${ }^{n 63}$

\footnotetext{
${ }^{62}$ Brian Massumi is an academic, writer and social critic. He teaches in the Communication Department of the University of Montreal. Massumi focuses on the philosophies of communication, electronic art, computer-aided design, architecture and the virtual.Massumi is also known for English-language translations of recent French philosophy, including Jean-François Lyotard 'The Postmodern Condition' and Deleuze and Guattari's 'A Thousand Plateaus'.

${ }^{63}$ Markussen, Thomas \& Thomas Birch. "Transforming Digital Architecture from Virtual to Neuro: An Interview with Brian Massumi". IntelligentAgent Magazine.
} 
If this is put into an architectural context, a vision of architecture is achieved by constructing the environment that triggers the changes that offer new forms of experience. As architects integrate new technologies more fully into their buildings, what they are really designing are possibilities of experience. They are not just building for practical function. They are becoming experience engineers.

The design of the Blur Building challenges the customary visual expectations of architectural style by presenting, at a first glance, nothing identifiable, a literal blur created by mist. Rather than addressing vision first and using vision to guide movement, as is usually the case, the Blur Building challenges vision in order to address movement first. The building is built to be vague, and then to become determinate through a process of cross- modal interaction that made a perceptual event of visiting it.

Integrating digital technology is not a necessary condition for architecture to address embodied perception in order to trigger experience events. But it can of course be a very powerful tool for this, because it allows cross-connections that were never before 
possible. This makes it possible to transduce changes occurring on one level of experience into events on a different level with infinitely increased flexibility, even at a distance.

This project demonstrates how augmented spaces and intelligent buildings generate new experiences and perceptions of space. The digital tool is used mainly for the translation of a concept into built form. The architects' ideas for an interactive media experience are achieved through advanced computerization techniques that generate climatic conditions, interactions between users through wearable computers, environmental experiences, and new multimedia experiences on the engulfing fog that functions as a dynamic video screen.

The Blur Building illustrates that blending of force fields, mappings, and meta-media are not essential to the generation of new media architecture, new experiences, or changed perceptions of space. The incorporation of physical computational infrastructure, digital technologies, and artificial intelligence has the ability to create changing user experiences, interactions within themselves and with the space, and alter the perceptions of space. 


\section{Urban Screens}

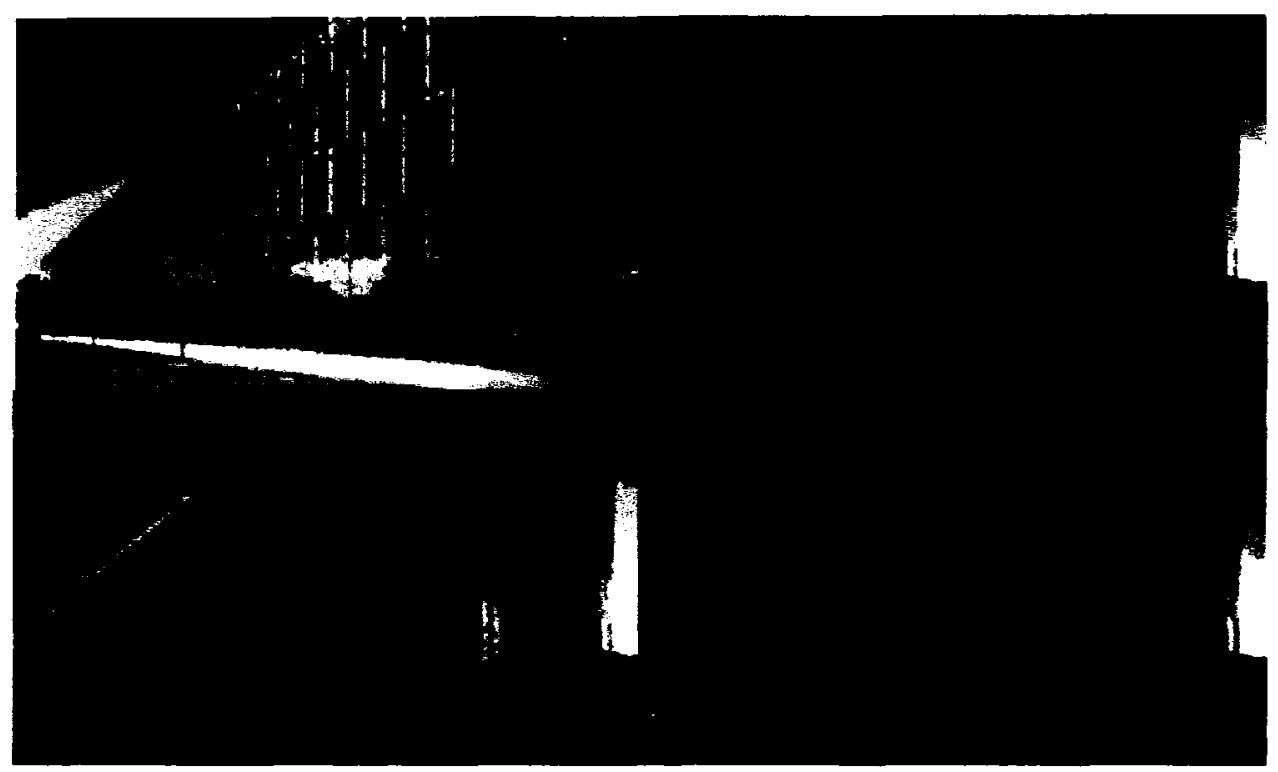

Fig. 8 Weber \& Hofer, Lentos Museum ${ }^{64}$, Linz, Austria, 2003.

Josef Hofer and Jerf Weber ${ }^{65}$ designed the Lentos Kunstmuseum in Austria as an oscillating three-story glass cube, 130 meters long by 30 meters wide, which fits seamlessly into the surrounding architectural landscape of the Danube River in Germany. It lies like a glass ship at anchor in Linz, Germany, and provides 8,000 square meters of space for internationally renowned art from the classical modern period to the present. Below deck, there is an underground library, museum shop, restaurant, café, and a bar.

\footnotetext{
${ }^{64}$ From: Lentos Museum Home Page. 15 July 2006. $<$ http://uww.lentos.at/en/index.asp?nr=2>

${ }^{65}$ For their design of the Lentos, Weber and Hofer won the 2003 Architectural Achievement of the Year award from the province of Upper Austria and the 2003 Client's Prize from the Austrian government.
} 
Method of Investigation:

The project employs representational techniques such as sketches, drawings, and compute rmodelling to translate the program into a built space.

Transformation through media and new media during design:

There is no transformation of space through media and new media. Computer media are used to generate the drawings necessary for the programmatic arrangement of space and form.

Transformation through media and new media after execution:

The museum is, at night, an outstanding part of the cultural mile along the Danube with its alternating illuminated facade in red and blue. The dominant architectural feature of the new structure is its semi-transparent exterior glass shell that delivers a luminous reflection of sunlight and the waters of the river flowing by. The design also enables users to walk through the lobby area designed as both an open sculpture hall and a transitional zone opening up a view of the Danube. 
Critique of the Project:

This project demonstrates how inside/outside appositions can be dissolved through media that creates translucent/opaque barriers while interior activities remain accessible through the transparent facades. The project does not quite dissolve the figure/ground appositions and remains a large sculptural object, which merges temporarily into the environment through reflections on its glass facades. However, in the absence of interactivity and dynamically changing content, the incorporation of light and color media remains representational. 


\section{TOWARDS THE DESIGN OF NEW MEDIA ARCHITECTURE}

New Media architecture is generated by the augmentation of physical space through technologies of surveillance, meta-media, and screen technologies. Augmentation of physical spaces through surveillance generates spaces of real-time communication, interaction, and shared joined experiences that can be rebroadcasting through the Internet. Augmentations of space through meta-media generate transformations of space through the mappings of force fields, latent fields, and environmental forces that affect a space through digital computational techniques. However, this translation does not change once the building is constructed.

Hence, the next stage of augmentation of physical space involves the use of interactive screens that generate mappings and metamedia. Interactive screens change the environments and experiences of users within this space. The augmentation of physical spaces through screens allows for interactive connections between real-time media, multimedia and meta-media, and a blurring between physical and virtual spaces, images and video. 
The design process is equally important for the translation of media into architecture. Projects such as the Trans-Port Pavilion, Real Space in Quick Times Pavilion, and Lentos Museum illustrate how design through representational tools such as sketches, drawings, and computer modeling translate the architect's idea of animate experience into a built media space. Projects such as Sendai Mediatheque illustrate the use of representational tools to combine structure with light and media as a concept that is translated into a built space that is augmented with screen technologies to generate changing experiences within the space. Projects such as the Blur Building illustrate how artificial intelligence and advanced computing applied to the physical structure of a space can generate a series of environmental effects and changing interactions within a space that is designed using representational tools such as drawings and CADD models.

At the same time, projects such as $103.8 \mathrm{Mhz}$ Blixembosch and Port Authority Bus Terminal illustrate the use of computers to generate space through criteria such as latent fields and environmental mappings. While these time-based computational architectures generate changing spaces in the design process, the 
translation of media into architecture remains virtual and does not further translate when the space is built. In this way, these strategies run the risk of generating formal expressionist gestures and the authorship of the architect is not clear. This process also denies any connections with site, scale, program, and functions within the architectural built space. Therefore, the computer - based design process can be either representational or experiential. It is the transformations of built spaces that become essential to generate dynamic changing experiences of users in a new media space.

An alternate design process can examine the programmatic arrangement of functions and spaces through representational tools such as diagrams, collages, and drawings as tools of ideation and concept. Elements of screen technologies can be used to arrange the site, programs, interior and exterior spaces, physical and virtual spaces. Interactive real-time communication technologies as joined shared experiences, history, and multimedia can be incorporated in this space by changing configurations and dynamic content. Through screen technologies embedded into the space, these strategies can establish media space as an augmented space 
through surveillance and media. The transformation of these surfaces, screens, and spaces through an augmentation of metamedia, mappings, and colors that dynamically change in relation with the media input can therefore lead to new, changing experiences of a space for the user, one that is constantly transforming. These shared experiences can be captured and rebroadcast through the Internet to similar physical and virtual pavilions allowing a new mode of interaction, communication, and experience offered by this media space.

The success of the theoretical and practical ideas in this alternate design process will be tested through the development of a media pavilion at the site of former theatres, rock shows, concerts, and bilingual activism in the multicultural, vibrant neighborhood of Adams Morgan which presently lies at the center of nightlife in Washington, D.C., USA. The changing experience of users through these augmented transformations of real-time media, video, multimedia, and meta-media shall be discussed in the following section. 


\section{CONCEPTUAL DESIGN OF NEW MEDIA ARCHITECTURE}

\section{The Project:}

In the present section, the alternate method of design and theoretical criticisms that draws upon the works of the media theorists as well as the architectural projects outlined in the preceding chapters is applied to the design of a media pavilion.

\section{Design Challenge:}

The main challenge of the design is the development of media spaces in which the experience of built space changes dynamically in relation to the media and new media housed within.

\section{Ideas to be tested:}

a. Computational time-based architectures are not necessary for the generation of new media architectures in which media dynamically changes into space and transforms the experience of this space.

b. Representational architectural design strategies generate functional programmatic spaces, which can be used to translate the designer's concepts of changing experience and interactions in physical space. 
c. Augmentations of physical space with screens, mappings, and meta-media through the incorporation of digital display technologies generate for changing experiences and alter our perceptions of space in media spaces.

d. Interactive spaces and augmentations through surveillance technologies allow for a shared joined experience of events in space and at the same time, allow for the re-transmission and broadcast of changing experiences to similar physical and virtual spaces.

\section{Design Strategy:}

a. Using diagrams to examine the relation between program, media and function/events on the site.

b. Developing drawings that accommodate the programmatic requirements of the project as well as allow for a continuation of ideas of media and new media in space.

c. Developing CADD models detail the materiality and spatial constructs of the project.

d. Assigning real-time media, communication media, Internet media and video media to the project to examine representational strategies of incorporating media in 
architecture on the basis of program and analyzing

subsequent interactions of users with the architecture.

e. Assigning meta-media and mappings to the physical spaces and analyzing subsequent interactions and experiences of users in this space.

\section{The Site}

Adams Morgan, (formerly $18^{\text {th }}$ \& Columbia Rd.), a vibrant, historical and multicultural neighborhood ${ }^{66}$ (Latinos, Africans, Jews and Americans) that has through time acted as the node of shopping, dining, night life, live arts, music, dancing, bilingual protests, rallies and liberal thought, cultural events and festivals. The history and present events of this neighborhood allow for the analysis of new media architectural programs through video, telecommunication and internet technologies that establish links between the various neighborhoods of Adams Morgan, the various countries of its inhabitants, and real-time joint experience cultural and social

\footnotetext{
${ }^{66}$ Please refer to Appendix 1 "Site History" for a detailed history of the Adams Morgan neighborhood as well as a detailed history of the site at Eighteenth Street and Columbia Road, Washington D.C. Please refer to attached material that includes a presentation called "history-site.ppt" that details a visual vocabulary of events on the site. Please refer to attached material for a video documentary titled "presentday-site" that outlines present day land use and cultural events on the site.
} 
events. Eighteenth \& Columbia Road SW in Adams Morgan is the site with a history of movie theatres, tragic historical events, psychedelic sound and light shows, political rallies, protests, antiwar activism, that is at present located in a surrounding of nightlife, clubs, bars, festivals, cafes, and private wireless internet zones for students and young professionals, with physical transport connections with surrounding ethnic neighborhoods and night life therein.

The history and identity of the site as place of cultural events and performances, and the changing nature of these interactions can be tested through new media incorporation. Real-time interactions between the users and the building in relation with the identity of the neighborhood are analyzed for continued identification of the residents with the site, and to generate new media spaces. The history and present events on and around this site allow for the examination of new media architectural programs that mediate the site by augmentations of space through surveillance, meta-media mappings and urban screens. 


\section{Design Program}

\section{Physical Program ${ }^{67}$}

Video Art Installation Plaza/Performance Area: 9000 square feet This plaza is used to study the blending of video art and architecture in dynamic changing configurations. The positioning of video panels takes into account the surrounding architectural walls and transforms them into an active media space that allow users to interact with them, by posting sms messages.

\section{Performance Stage: 750 square feet}

This stage connected to the Video Installation Plaza allows for the historic link between past sound and light performances, the stage of past theatres on the site, and present day street festivals and shows on Eighteenth Street, transforming the site into a focal point of entertainment as it had been between 1917 and 1967.

Dance Hall/Concert Hall/Ball Room: 2000 square feet This hall draws on the present day club culture of the Adams Morgan area and provides another avenue for residents of the city and this neighborhood. This hall is incorporated to study how a

\footnotetext{
${ }^{67}$ Please refer to accompanying figures $9-43$ for drawings and digital models.
} 
video and Internet media space that generates mappings from the performances and music being played throughout all the walls of its interior and exterior transforms the perception of space.

Exhibition Space: 4500 square feet

This space extrapolates the plinth of past theatres along the Columbia Road side of the site. The past and present significance of Adams Morgan to artists in terms of meeting and display space continues with the presentation of art works in the exhibition space that is publicly viewable across the transparent facades of this exhibition space when video and telecommunication media are alternated.

Workshops/Studios: 4500 square feet Workshops and studios are incorporated in the design to provide spaces for the creation/editing of digital new media and video art. The digital content created by artists and students projected onto the facades of the studios generates dynamic changing facades and spaces within the architecture which allows for the simultaneous display of several art works or a single video installation that spans across all facades of the workshops and 
surrounding exterior facades of the designed media pavilion in animated sequences.

Cafetaria: 1250 square feet

The cafeteria acts as a media pavilion on the interior and the exterior. It is suggested that the media walls, a fusion of transparent and opaque walls, be used to display videos and images on the basis of keywords entered by the users of the café through their cellphones. Correspondingly, the surrounding panels of the cafetaria momentarily become ambient spaces that generate color mappings derived from the ambience of the image/video being displayed on the basis of the keywords input by the users. The resulting meta-media are projected intermittently on the interior and exterior facades or urban screens of the media pavilion. The resulting morphogenetic, augmented, meta-media mappings are analyzed.

Theatre/Auditorium: $\mathbf{4 0 0 0}$ square feet with seating for 600 persons, Stage, projection room, make-up rooms, design office, production office, stage office, workshop, studios \& prop storage. 
The theatre/auditorium allows for movie screenings, theatre shows, musical performances and discussions. Through video telecommunication media and the Internet, musical, theatrical performances and scholarly/political discussions are set up as multi-channel portals receiving inputs from several locations. This allows for new forms of collaborative experiences for the users of the theatres. At the same time, the collaborative performances are mapped onto screens on the exterior of the theatre allowing for a broadcast of all performances and events to the surrounding neighborhood with provisions for event information available to users with cellular phones.

\section{Urban Screen:}

The urban screen is an important visual element in this design. It portrays the mapped meta-media within the galleries and spaces of this pavilion along with real-time net and video events as generated joint experiences for the residents of Adams Morgan. The scale and number of channels of visual information alternate according to the event being portrayed and allows for interaction with the users, who can upload text, images and video via cellular phones. The dynamic screen alternates between transparent, translucent and 
opaque and allows for a dynamic blending of landscape and architecture, between built space, program and landscape. Integration between screen and environment is sought. The urban screen supports the idea of public space as space for creation and exchange of culture and the formation of public sphere by criticism and reflection generated through media.

\section{Street Level Interactive display screens:}

The built project traces the plinth of the two theatres that were present on the site between 1917 and 1969.The new urban plinth is used to study the morphogenetic blending of media and architecture through a historical representation of past events at the site and the neighborhood that transform to allow present day video communications between the multi-ethnic residents of Adams Morgan with their parent countries. These display screens when interactive allow users, residents and tourists to experience the site and the neighborhood in new ways through media. The experience remains representational. 
Bus Stops 2 Nos.: 750 square feet

Bus stops are equipped with interactive video technology. Thus communication between waiting people at different bus stops is made possible. If one likes to, one can start a "video conference" with somewhere else waiting people. The subjective safety feeling is increased, and by means of communication with other humans boredom of waiting can be overcome by nice conversations . Video communication instead of video surveillance, voluntarily and transparent, but at the same time entertaining.

In the context of site and neighborhood, these chat stops connect the users of these stops with users of other chat stops along the routes to final destinations toward the Latin neighborhoods and the African neighborhoods. Approaching buses to destinations trigger a momentary shut down of video channels and transform the chat stops into a visual array of pausing lights and colors, and a return to transparency for visual access to the bus routes.

Main Foyer: 2000 square feet

This mediation examines a morphogenetic blend of design program with physical connections and history of the site through video. The 
Main foyer traverses across the media pavilion and acts as a link between the two bus stops. This foyer is mediated with interactive panels that depict the history of the two theatres on this site, political protests, liberal activism and past psychedelic sound and light shows that were performed on this site through its history.

Artists Space: 7000 square feet

This space allows artists and sculptors to create physical works of art. These works of art are digitized and mapped onto the surrounding transparent panels of the architectural façade. This allows for select art works in process to be part of the public domain through media. Completed works are mapped onto the exterior walls of the architectural envelope at the level of the artist's space, or enlarged to be displayed onto the full urban screen façade, thereby allowing for and accepting connections and commentaries.

Audiovisual Library: 7000 square feet This space facilitates the creation, generation and archiving of audiovisual materials and art works that are displayed on the urban screens and video art pavilion. The exterior walls remain 
transparent and reveal the activities within. When users access select archives, the artwork is mapped onto the exterior façade of the library at its level, or it is mapped onto the entire urban screen. At the same time, the ambient colors of the media work are mapped onto the other walls of the library resulting in dynamic transformations of the façade and the interior architectural space with every exhibit accessed.

Multimedia Library: 7000 square feet

This space operates similar to the audiovisual library in terms of exhibit generation, archiving and spatial transformation at its level.

Staircases/Lifts: 1000 square feet Staircases and lifts provide visual connections between various spaces of the media pavilion. A central staircase connecting various media spaces is developed as a media well that displays visuals of the exhibits, artifacts and works performed and developed within the pavilion at its various levels. Users select the level that they are visiting at the ground level and visuals traverse across the screens of the media well previewing the information, programs and events at each level. 
Administration \& Toilets: 1500 square feet

Administration \& Toilets are provided as a programmatic functional element for the workings of the physical pavilion only.

\section{Virtual Program}

- Real-time Collaborated live discussions, musical and dance performances transmitted and broadcast over the net.

- Video Telecommunication between the Built Environment and Media Panels in different embassies/consulates in South American and African countries

- Urban Screens for multi-cultural content, joint experiences

- Digital Art, Video Art Festivals \& Screenings: Displayed and Broadcast

- Multimedia Messaging: Displayed and Broadcast

- Interactive installations/neighborhood boards for residents and visitors and tourists.

- Video Projections for alternative moving image content

- Electronic Public Artwork exhibiting the faces of the community

- Public Wi-fi Zone 
- Broadcast content (artwork, metamedia mappings, morphogenetic blends, ambient transformations) transmitted over the internet and to cellular phones within the space.

\section{Demonstrated Design Theories}

The design process assigns programmatic elements and spaces through the spatial organization of events on the site (The Adams Morgan Day Festival) through the primary placement of the video art pavilion that allows for the appropriation of site and this function. The placement of exhibition spaces along Columbia Road along the profile of the site establishes this space as a portal for visual connections (a dissolution of figure/ground), a portal for real-time video connections on its interactive panels (augmentation through surveillance), as well as for the representation of interactive, historic events on its facades (augmentation through mappings and multimedia).

Spaces such as the cafetaria, multimedia library, audiovisual library, and discotheque when augmented with interactive screen technologies act as representational spaces through image and 
video, that transform through meta-media mappings to generate changing experiences of these spaces on the basis of the input data (music, art work, image and video).

Spaces like the chat stops augmented with real-time surveillance and communication technologies transform the experience of waiting for a bus into an experience of informal chatting, information gathering, and event notification. An approaching bus transforms this space into a space of changing colors, lights, transparency and at the same time, generates visual connections with the surroundings and the street as an augmentation through metamedia experience.

The interactive urban screen allows for a clear viewing of activities within the pavilion thereby dissolving the boundaries between inside and outside space. The augmentation of this screen through mappings on the basis of the exhibits accessed in the multimedia and audiovisual library generates changing experiences of this screen, and correspondingly, the pavilion. At other times, exhibit mapping extends to the full screen and changes the spatial experience. The transformation of this screen through cultural 
programming and sports events establishes a new experience of space and generates identity for the pavilion as a portal of communication, information and entertainment.

The multi-channel real-time shared experience of musicians and thinkers with live performers in the theatre establishes this space as a portal of new forms of real-time interaction that is re-transmitted and broadcast to similar physical and virtual pavilions through the internet. This re-transmission of data is also a virtual program of the urban screen, discotheque, multimedia library, audiovisual library and cafetaria that collects all the visual information of media and meta-media mapped and interacted with in this pavilion and broadcasts it through the Internet.

Therefore, this feature of the pavilion establishes it as a live signal that is no longer receiving data and being transformed by it. The pavilion is, at the same time, broadcasting new forms of interactive experience live through the Internet to similar physical and virtual networks and pavilions. 
The virtual body becomes an interactive participant immersed in active transformations of media, video media, real-time communication media, multimedia, and meta-media before it dissolves through the lens of the video camera and the digital video capture device and re-transmits itself to new spaces and places, manifesting itself as telepresence and memory.

This design process proves that computational time-based architectures are not necessary for the generation of new media architectures in which media dynamically changes into space and transforms the experience of this space. Representational architectural design strategies generate functional programmatic spaces, which can be used to translate the designer's concepts of changing experience and interactions in physical space. The augmentations of physical space with screens, mappings, and meta-media through the incorporation of digital display technologies generate for changing experiences and alter our perceptions of space in media spaces.

Interactive spaces and augmentations through surveillance technologies allow for a shared joined experience of events in 
space and at the same time, allow for the re-transmission and broadcast of changing experiences to similar physical and virtual spaces. Therefore, the experience of built space changes dynamically in relation to the media and new media housed within through the augmentation of physical space with technologies of surveillance, mappings, meta-media, multimedia and real-time video media. 


\section{CONCLUSION}

The present thesis is an architectural investigation of the process of translation of changing media (real-time video, multimedia, internet) and new media (meta-media) into static physical space. The changing relationships between media, new media, and architecture are explored in an effort to use the effects of these media to transform space.

Lev Manovich identifies new media's in its flexibility of not being anchored to any specific output. He defines the concepts of "metamedia" as new structures generated out of software translations of media objects. Electronic Media (multimedia, real-time media, video media, internet) and New Media (mappings and meta-media) are time-bound artifacts created within their specific temporal contexts with the potential of instantaneous dynamic change. At the same time, these media generate changed perceptions due to dynamic physical and spatial relations connected across distances that cannot be completely experienced, but at the same time, are now accessible and habitable. 
According to Marcos Novak, physical architecture is static and has lost the potential to incorporate the dynamic changes in spatial qualities and experiences that are realized through digital technology and transmissible architectures. Architecture changes through time as well. However, this change is implied over the life of a building. Hence, the time scales of change between media and architecture are different. In relation to media, the temporal change in space is insignificant, and architecture is rendered as utilitarian. Furthermore, Novak suggests that architectural design processes using representational tools such as drawings and models (manual and CADD) can no longer transform space.

Media theorists have explained the relation between media and architecture as 'blurred' through concepts such as 'electronic extensions' and 'acoustic space' (Marshall McLuhan), 'surveillance' (Paul Virilio), 'digital data translation' (Marcos Novak), 'augmentation', 'meta-media' and 'screens' (Lev Manovich), 'continuum' (Christina McPhee), and 'performative interfaces' (Mirjam Struppek and Tore Slaatta). At the same time, architects have successfully examined the relation between media and architecture through their theoretical interpretations in projects such 
as Trans-Port Pavilion (Kas Oosterhuis \& Ole Bouman), RealSpace in QuickTimes Pavilion (UN Studio), Off the Road/103.8 MHz (NOX Architects), Port Authority Bus Terminal (Greg Lynn), Rosenthal Center for Contemporary Art (Zaha Hadid), Sendai Mediatheque (Toyo Ito), Blur Building (Diller \& Scofidio), and Lentos Museum of Art (Weber \& Hofer).

Through the above studies, different modes of design investigation and translation (drawings, modeling, CADD, digital computerization of environmental forces) used by the media-space architects are analyzed to examine whether they allow for the translation of media into the built space. Media and architecture come together during the design stage as under:-

a. To translate the designer's ideas of perceptual experience through the use of representational design tools.

b. To translate the designer's ideas of perceptual experience through computerization of environmental effects using artificial intelligence and neural network software programs.

c. To translate the latent and environmental force fields to generate animate experiences and new spaces. 
Media and architecture come together after execution as:-

a. The use of representational tools is used to construct the physical space and perceptual experiences are translated through the architect's ideas.

b. The use of artificial intelligence and neural networks generates new forms of interactions, effects and experience of space.

c. The translation of latent and environmental fields does not carry forward after the space is built. Therefore, media no longer transforms this space.

The process of transforming new media into space does not necessarily involve time-based digital computerization techniques, as these methods do not transform physical space after it is built like they do in the virtual domain. The spatialization of time-based media can be a meta-media mapping within a physical space that transforms the experience of the user. The history of a place and events can be incorporated into physical media space as interactive representations through media technologies built into a physical space. A blending of physical and virtual space generates a new media experience/event in a space and allows for the transmission 
of new forms of interaction and joined experience through the Internet. Hence, an alternate method of design of media spaces can be achieved from a translation of animate experience through media and new media into built space using representational tools such as diagrams, collages, drawings and models to translate the concept of media transformation. This method is as under:-

f. Using diagrams to examine the relation between program, media and function/events on the site.

g. Developing drawings that accommodate the programmatic requirements of the project as well as allow for a continuation of ideas of media and new media in space.

h. Developing CADD models detail the materiality and spatial constructs of the project.

i. Assigning real-time media, communication media, Internet media and video media to the project to generate changing interactions of users with the space.

j. Assigning meta-media and mappings to the physical spaces and analyzing subsequent interactions and experiences of users in this space. 
This alternate design method is used to demonstrate the theoretical issues through the design of a Media Pavilion in a vibrant neighborhood called 'Adams Morgan' in Washington D.C. wherein changing interactive perceptual experiences are generated in the built space on the basis of the pavilion's physical-virtual program by blending of space, multimedia, metamedia and video media.

The project employs digital screen technologies (liquid crystal displays, and E-Paper) to develop spaces that, when transparent, allow for visual connections between inside and outside spaces, and, when mediated, allow for real-time communication, real-time mappings of color and sound, and meta-media mappings in changing configurations across different spaces of the pavilion that transform the experience of space dynamically across the pavilion. The interactive nature of these screens that allows for the production and uploading of cultural content by users enhances this experience. The broadcasting of these experiences and interactions through the Internet establishes a transformation and transmission of perceptual experience to generate new digital transformations elsewhere in similar physical and virtual pavilions. 
Imagine media space as an intelligent and neural soundscape that is sampled and visualized through digital tools from real-time mappings of sound, video and latent environmental information fields. The spatialized and interactive image-sound-space becomes a conscious neuro-sensual media experience. Interactive panoramas trigger indeterminately and transform architectural space physically. The space of media uses sound and video mappings and meta-media to generate changing spatial dynamics. Interactive media become form-sensing tools that transform architecture instantaneously.

The shape of the media-art-space shifts dynamically as it engages in the interaction of events and emerges from these interactions. Virtual and physical spaces interpolate across the multidimensional volumetric surfaces of the new media architecture. The architectural interface becomes a physical, real and transmissible illusion that networks with similar conscious, physical and virtual interfaces.

"Here and there, sick lamplight through window glass taught us to distrust the deceifful mathematics of our perishing eyes". (F.T. Marinetti, Futurist Manifesto, 1909) 


\section{DESIGN DRAWINGS AND DIGITAL MODELS}

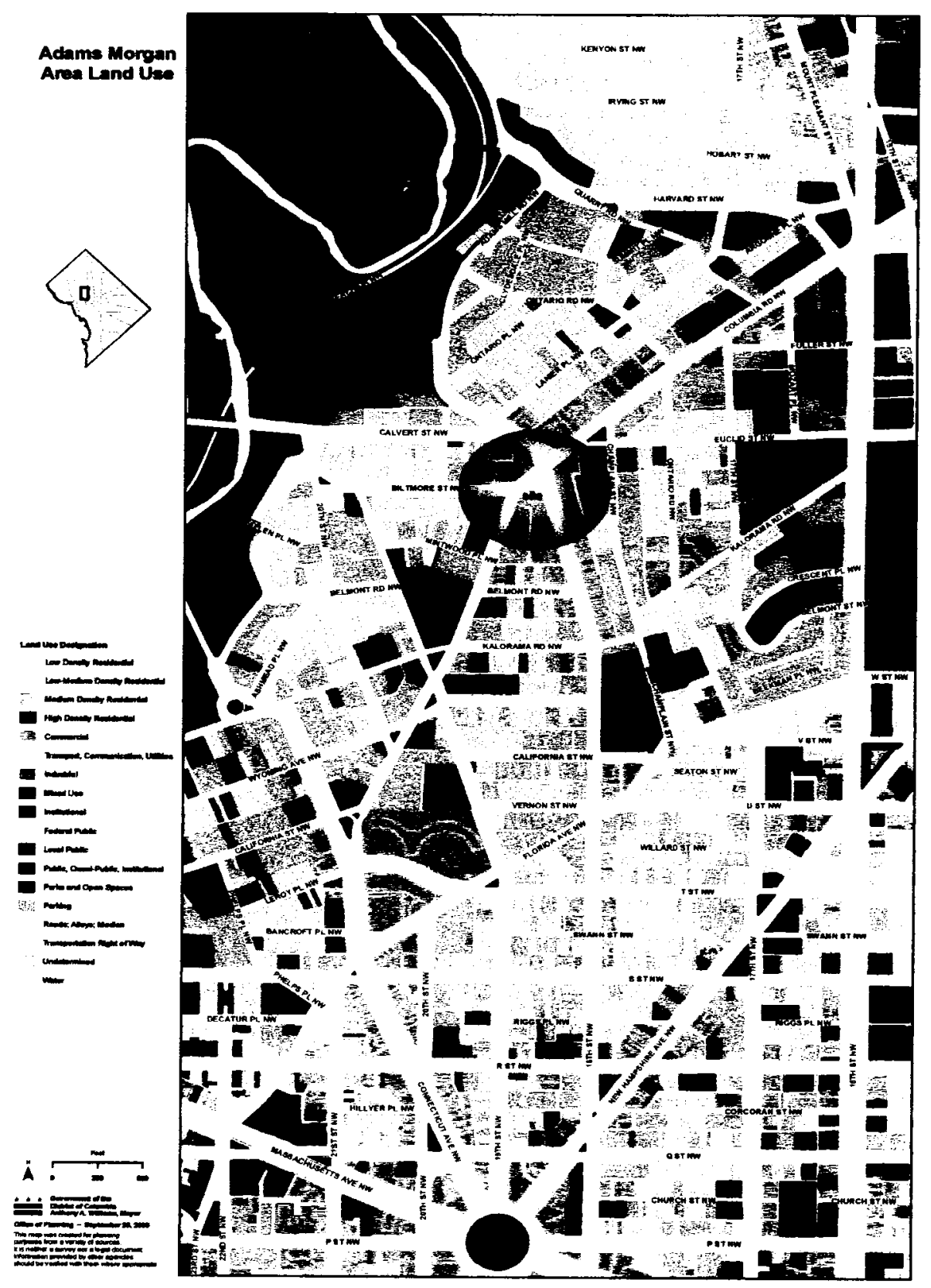

Figure 9. Land Use Plan, Adams Morgan, Washington, D.C. 

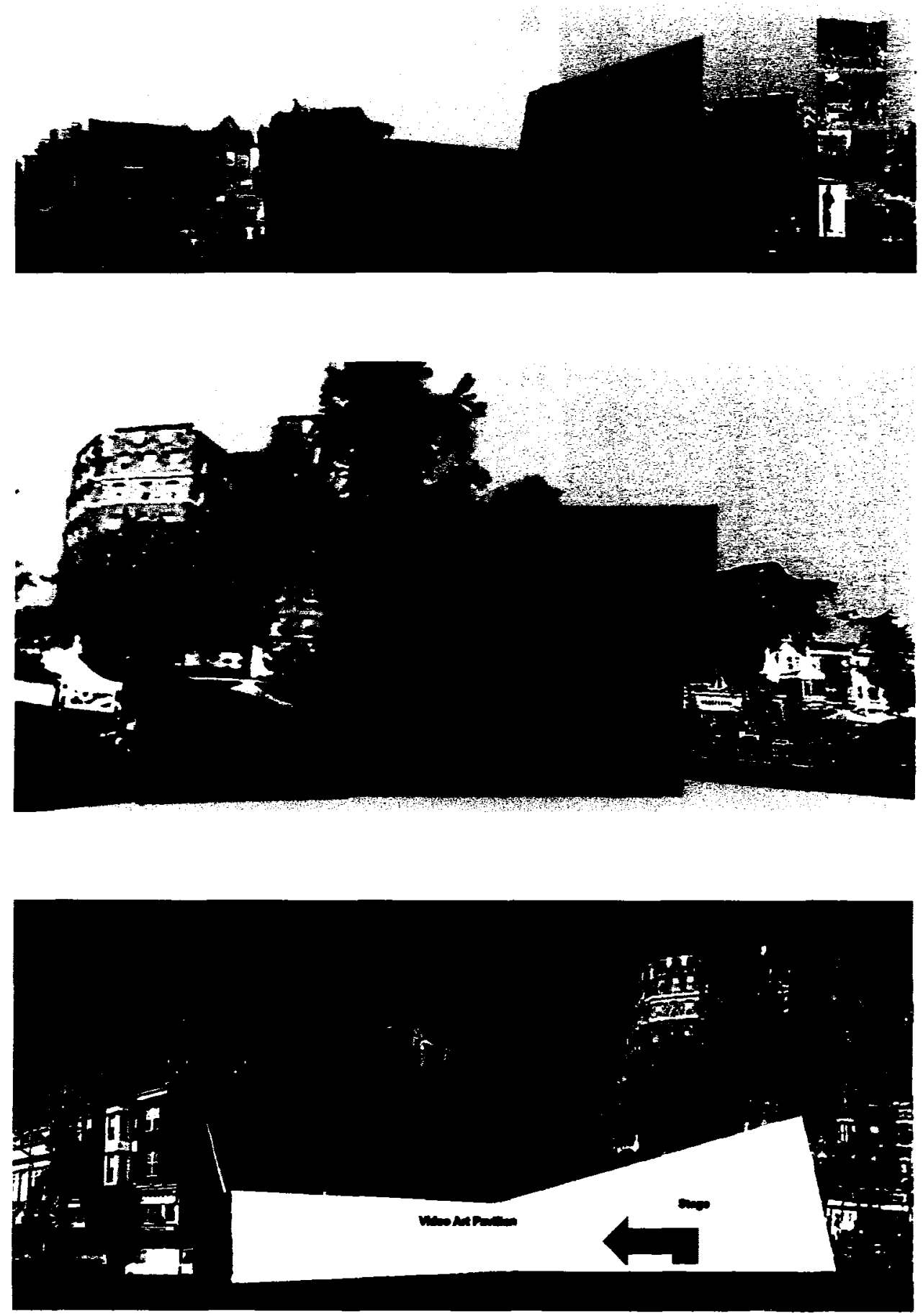

Figures 10,11 and 12. Concept Diagrams 


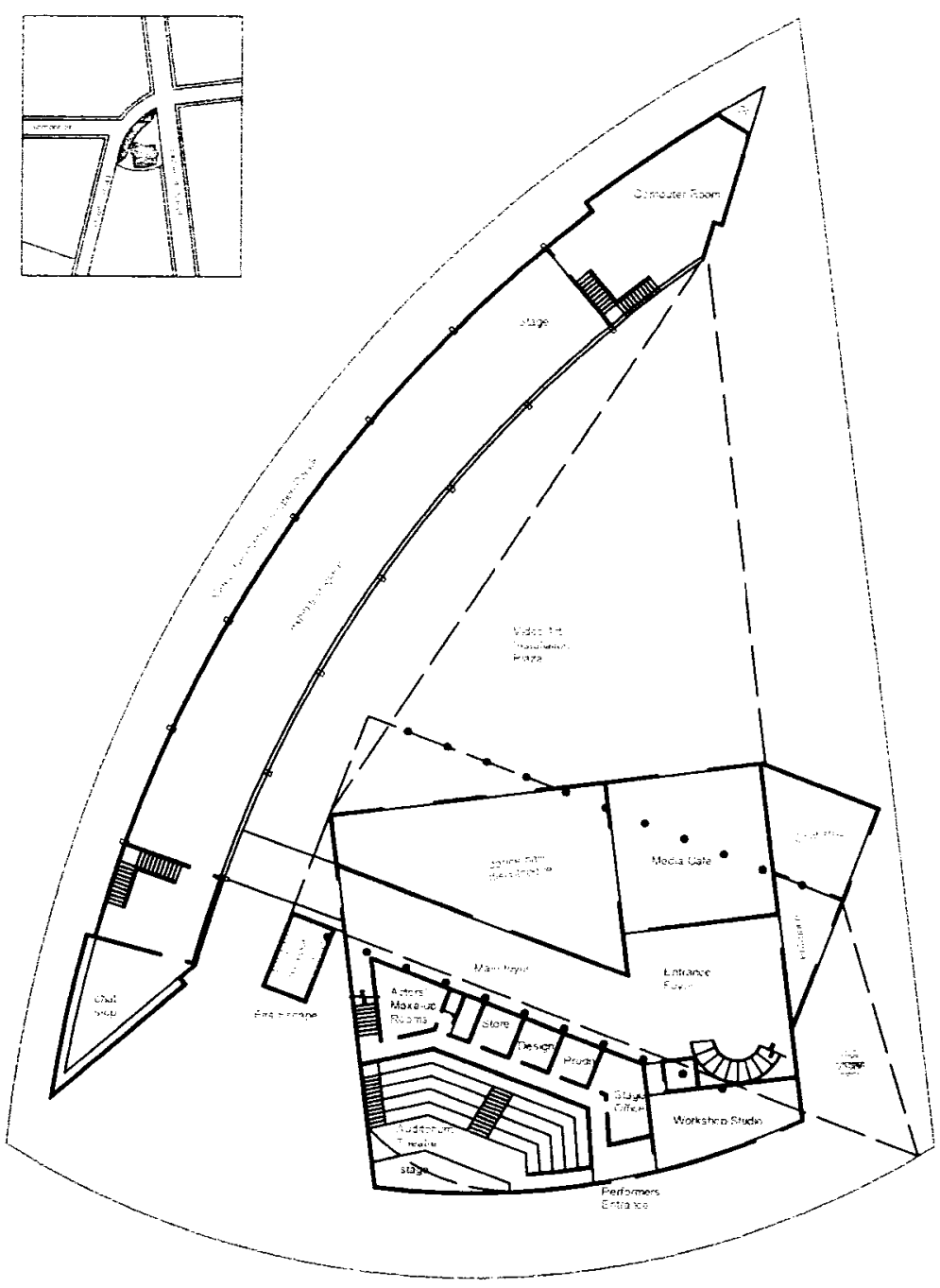

Figure 13. Level 1 Plan 


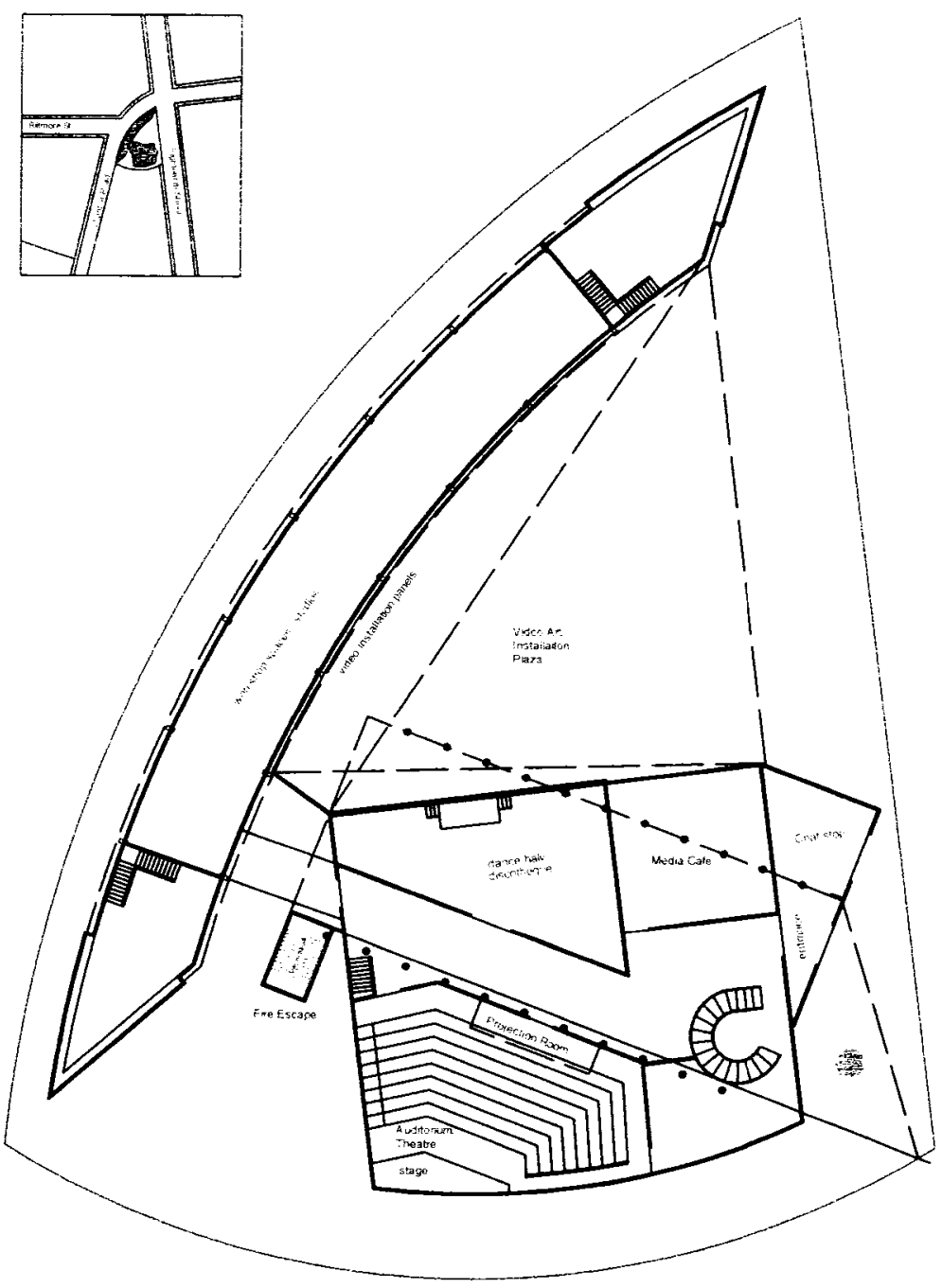

Figure 14. Level 2 Plan 


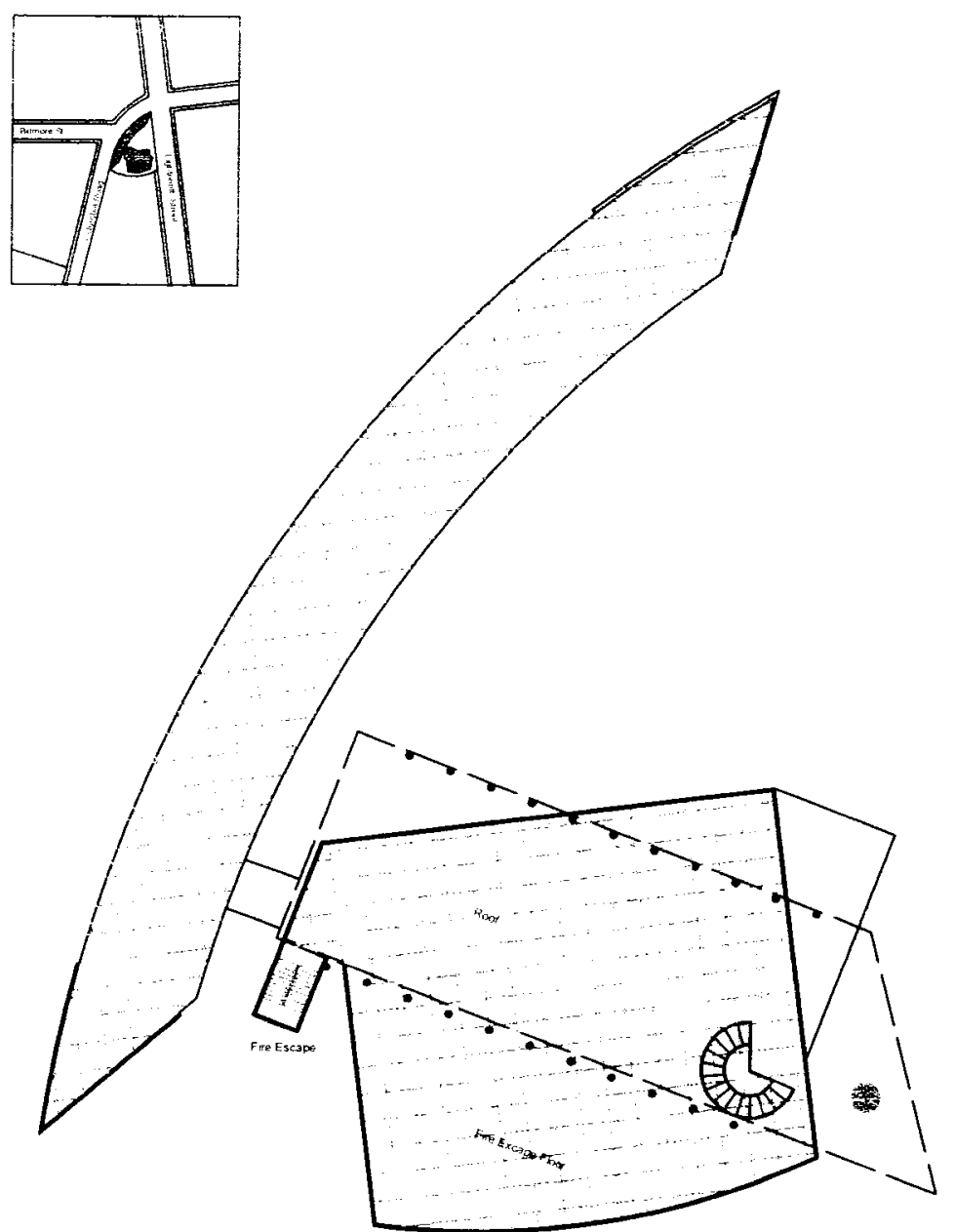

Figure 15. Level 3/Terrace Plan 


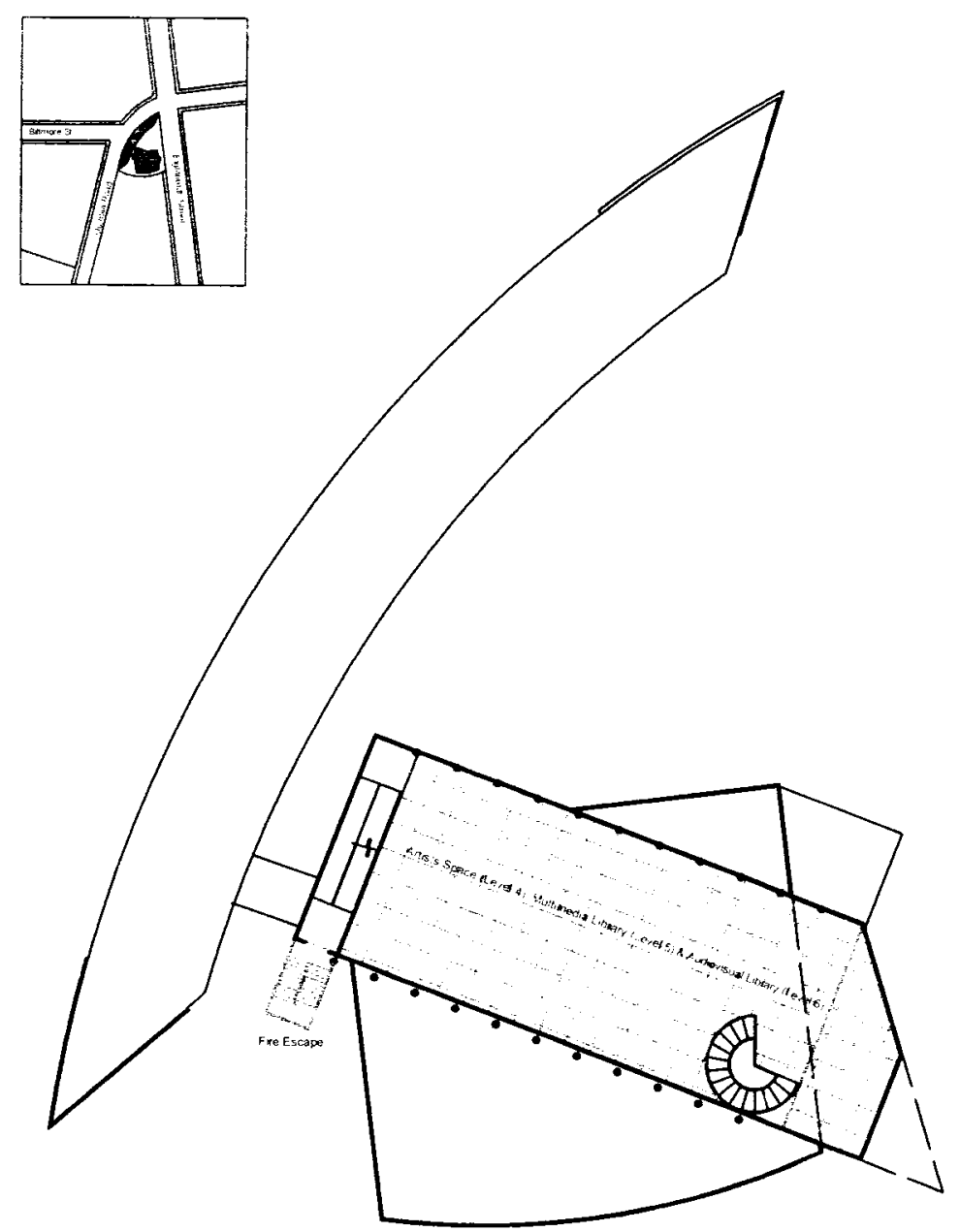

Figure 16. Level 4, 5, \& 6 Plan 



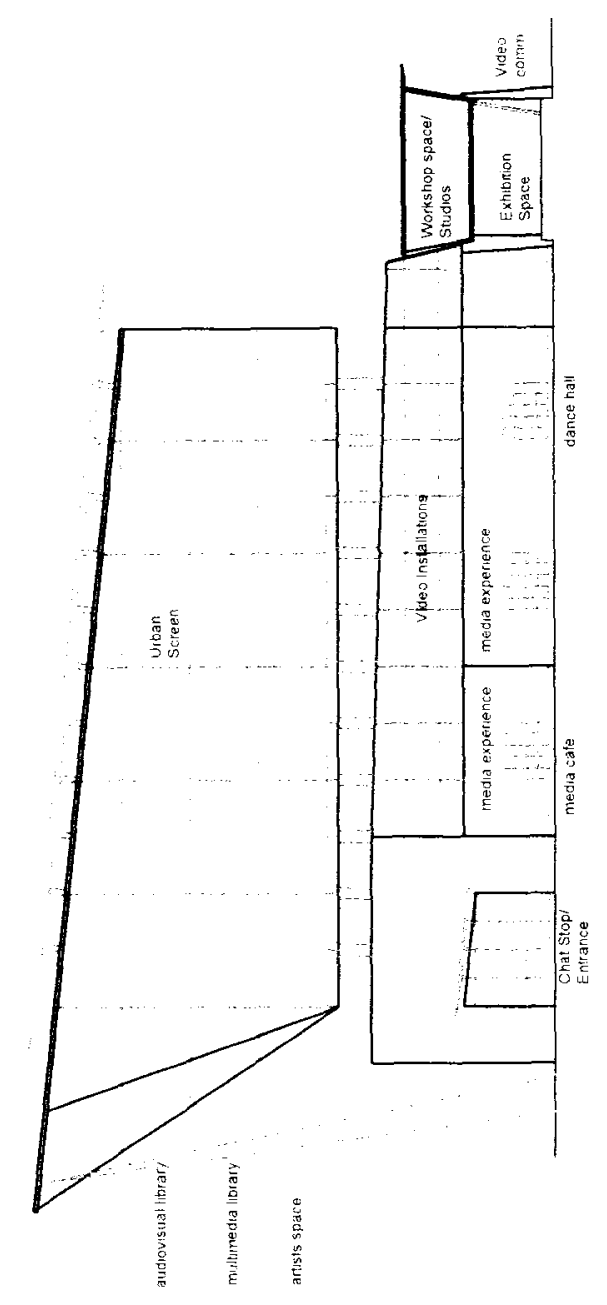

Figure 18. Sectional Elevation

Reproduced with permission of the copyright owner. Further reproduction prohibited without permission. 


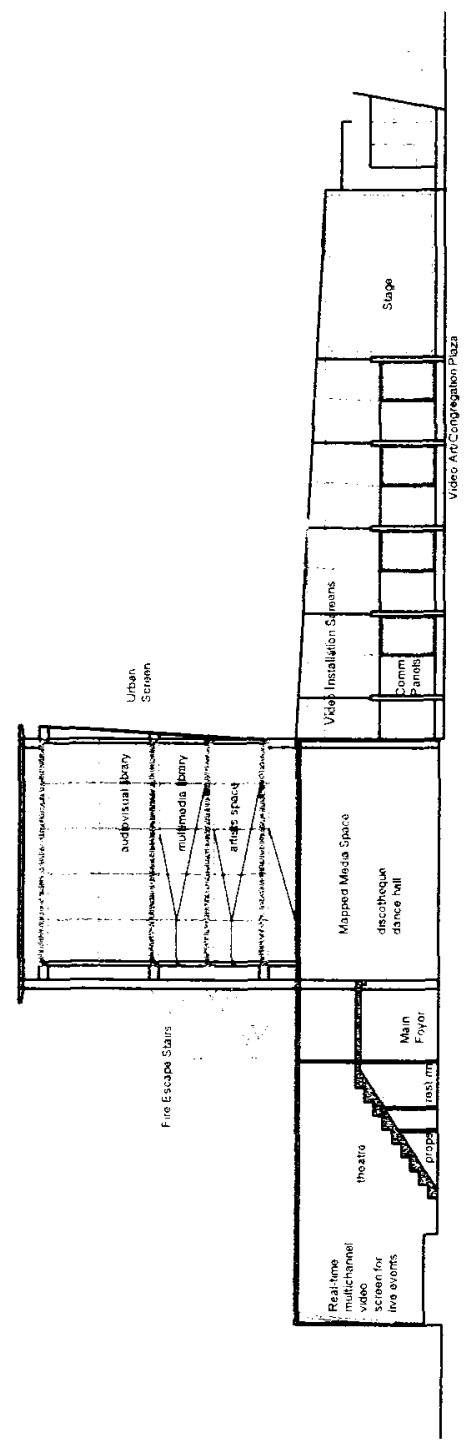

Figure 19. Sectional Elevation 

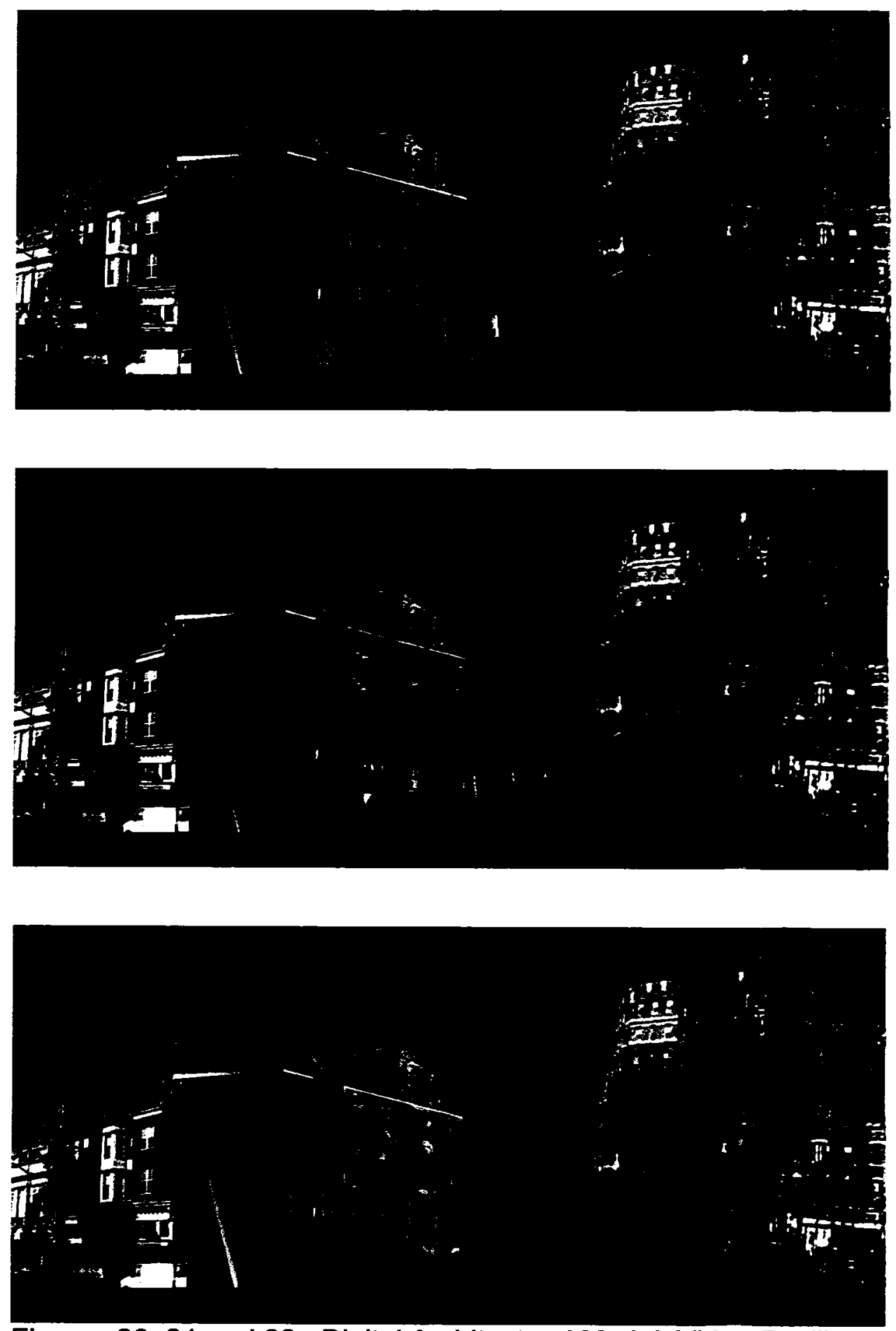

Figures 20, 21 and 22. Digital Architectural Model: Video Pavilion 

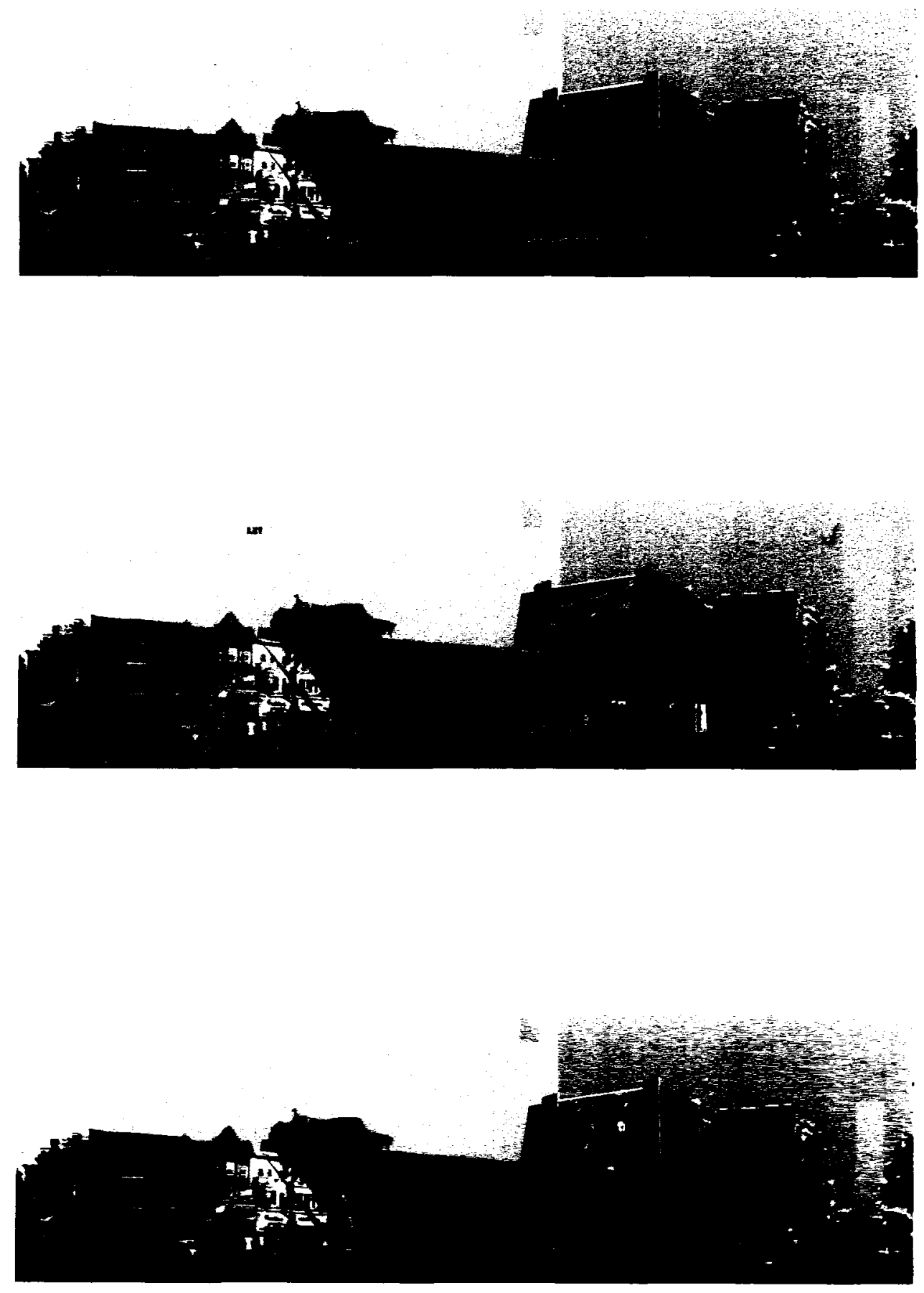

Figures 23, 24 and 25. Digital Architectural Model: Exhibit Space 

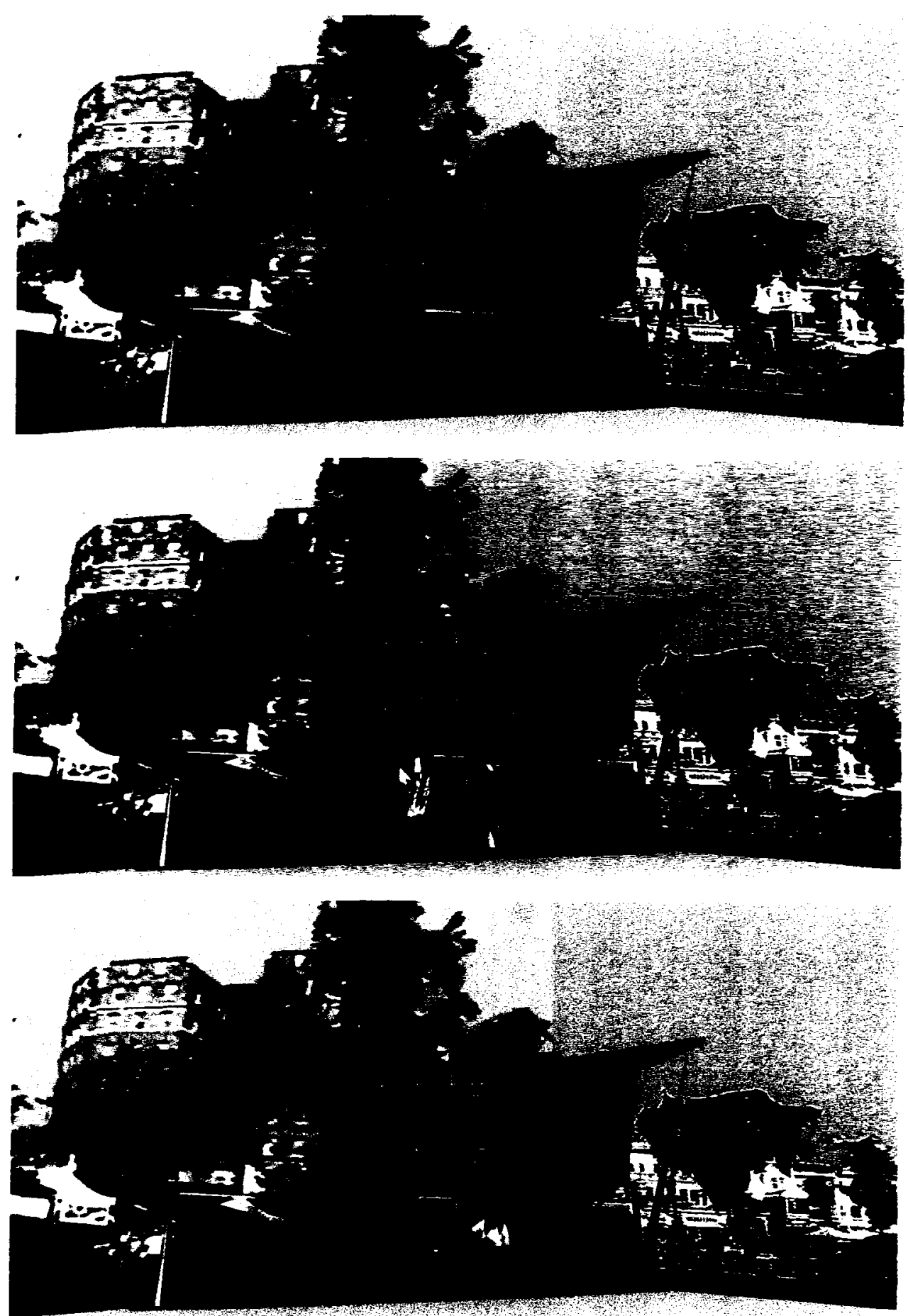

Figures 26, 27 and 28. Digital Architectural Model: Theatre 

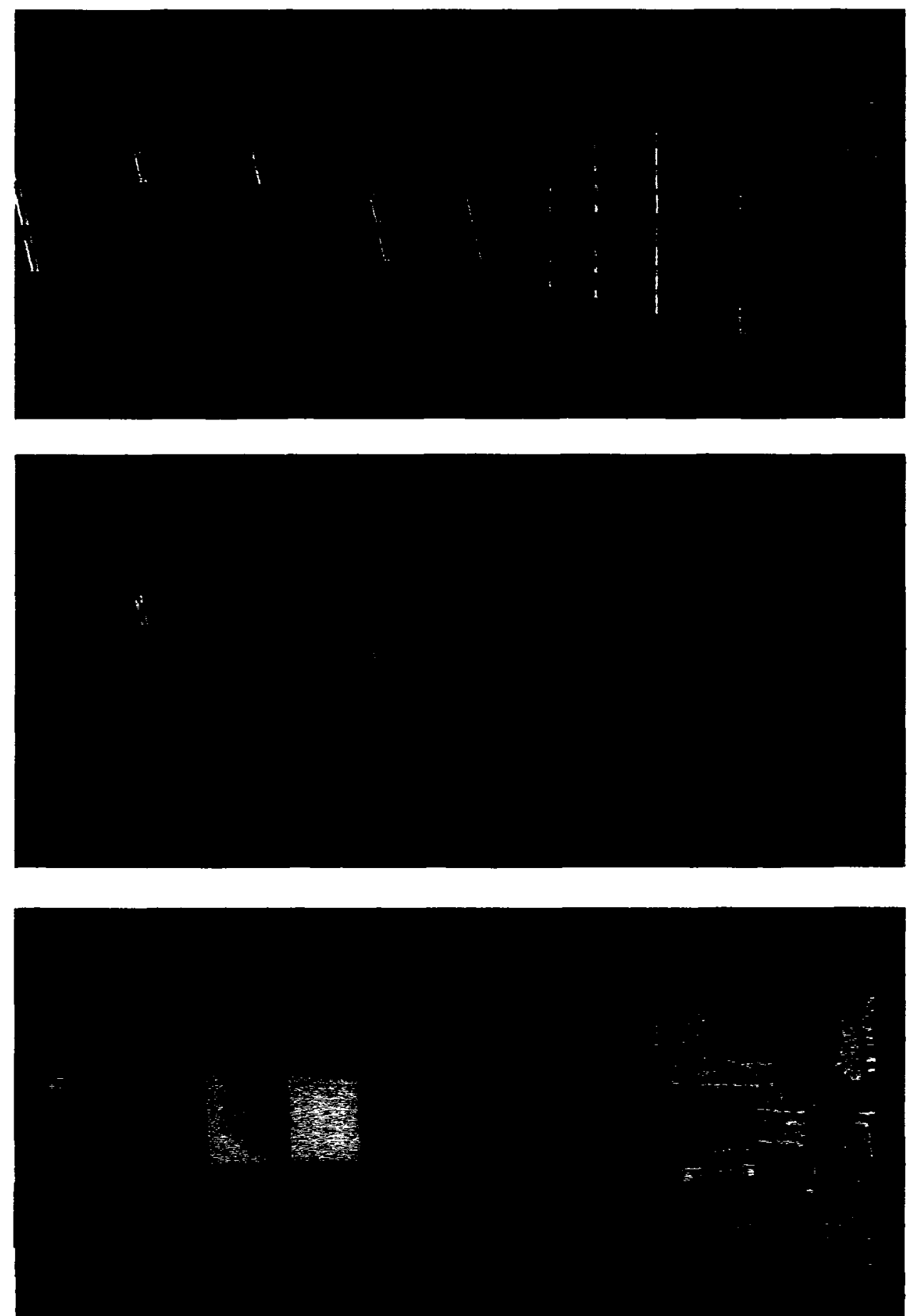

Figures 29, 30 and 31. Digital Architectural Model: Chat Stops 

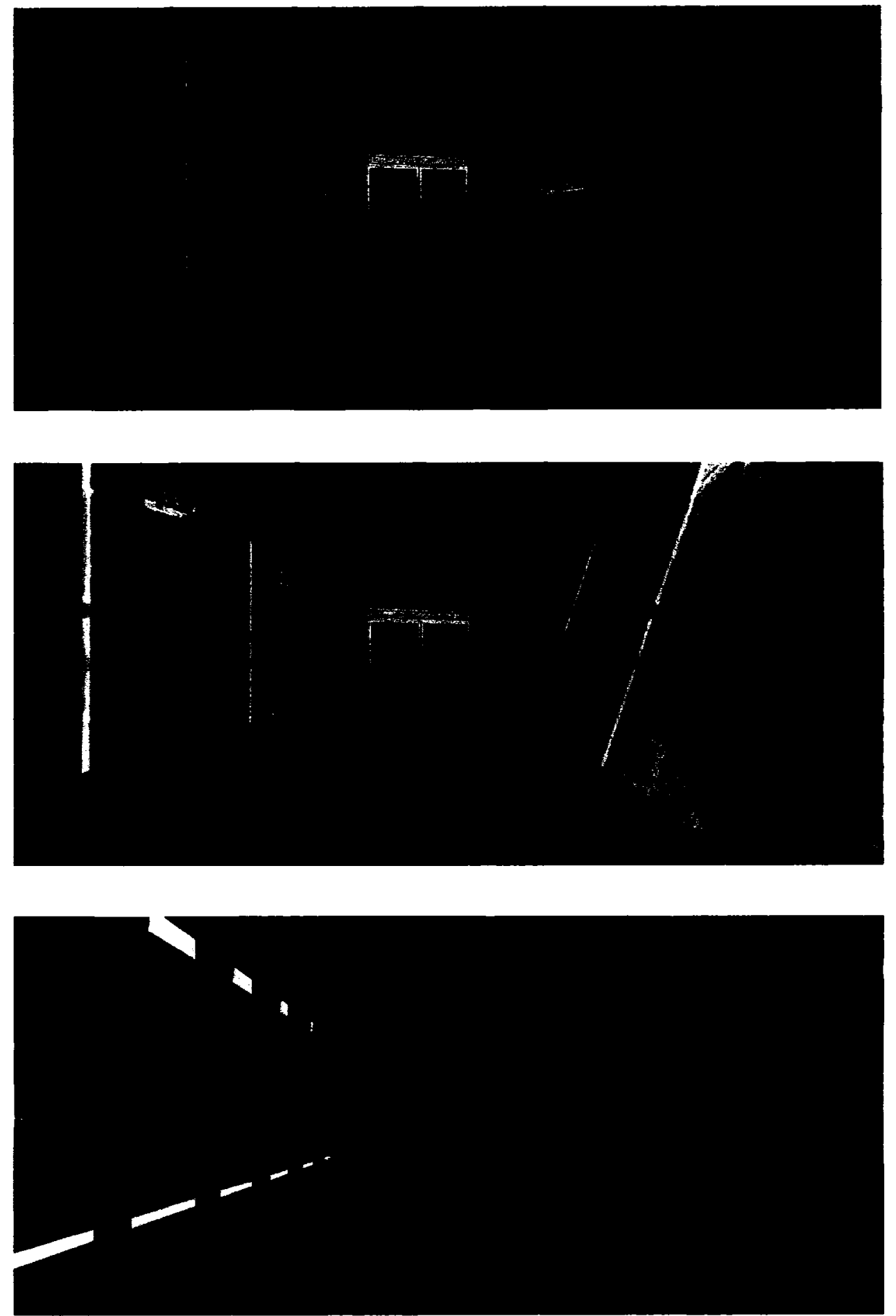

Figures 32, 33 and 34. Digital Architectural Model: Central Foyer 

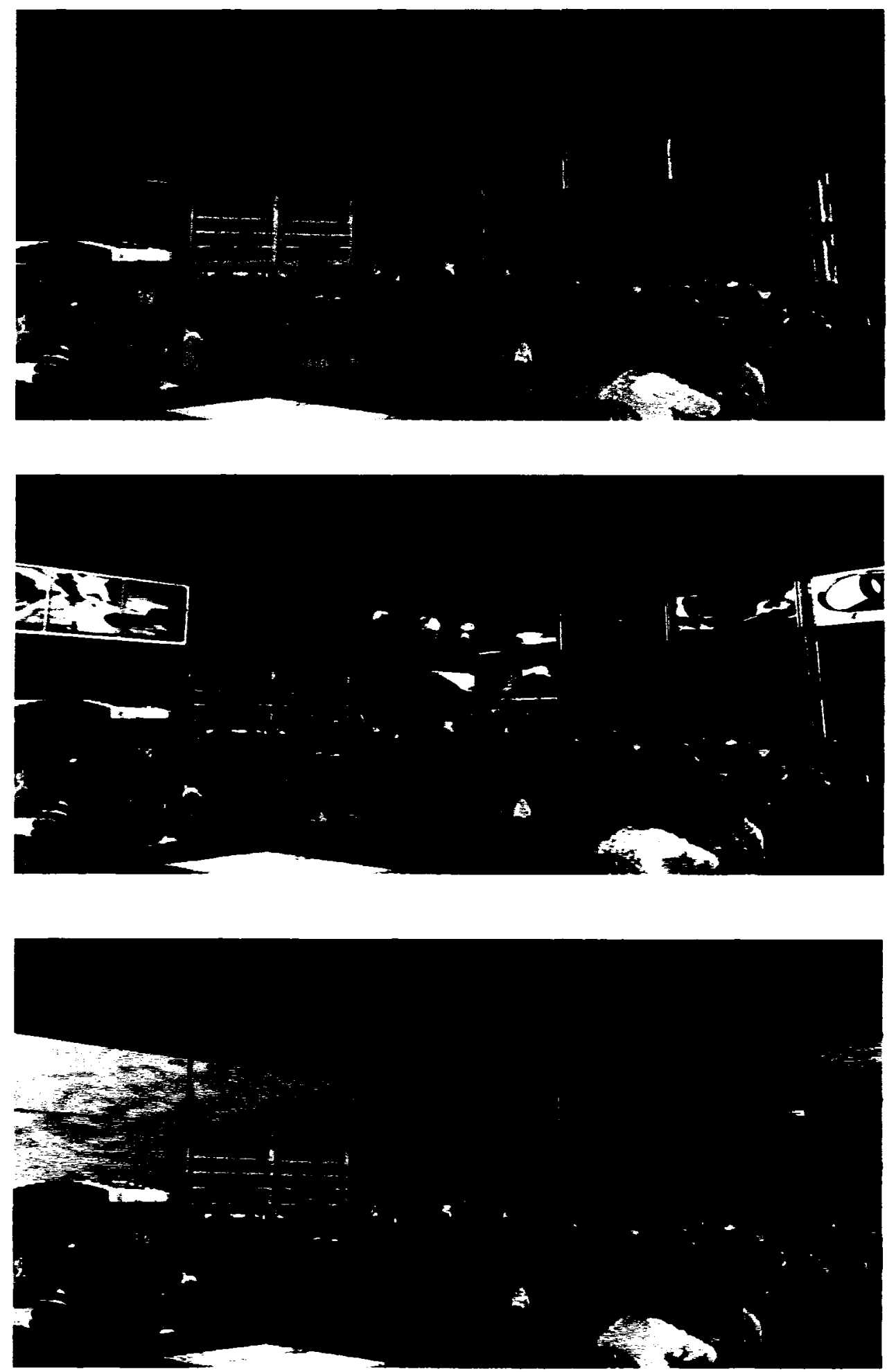

Figures 35, 36 and 37. Digital Architectural Model: Cafetaria 

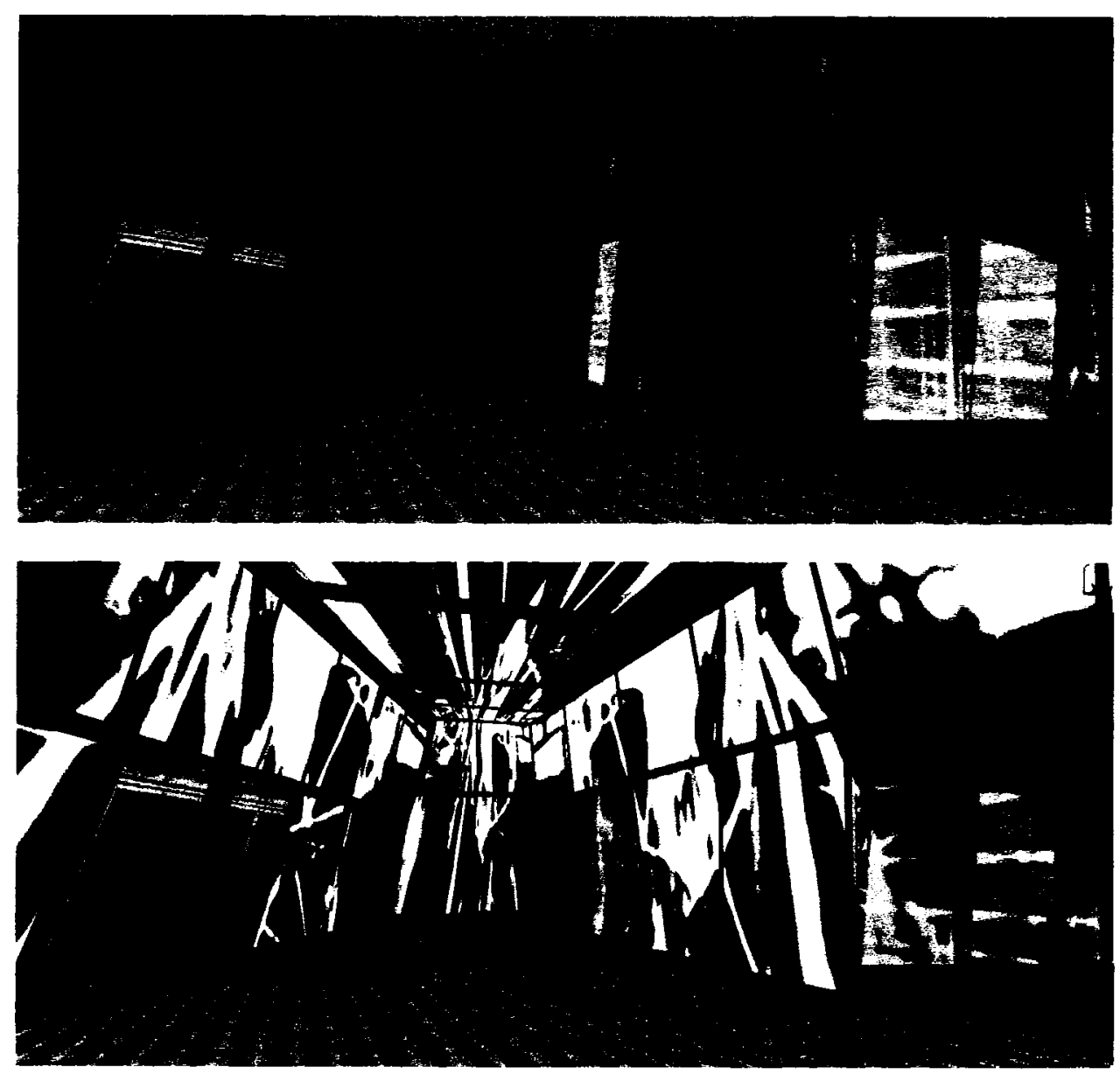

Figures 38 and 39. Digital Architectural Model: Discotheque

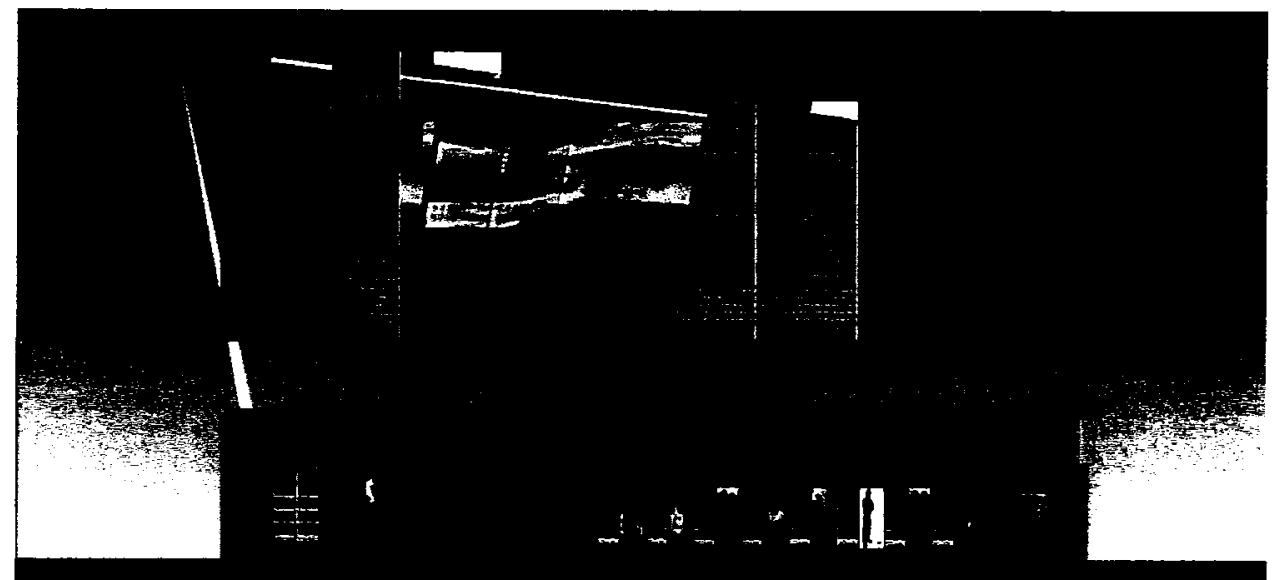

Figure 40. Digital Architectural Model: Front Elevation 


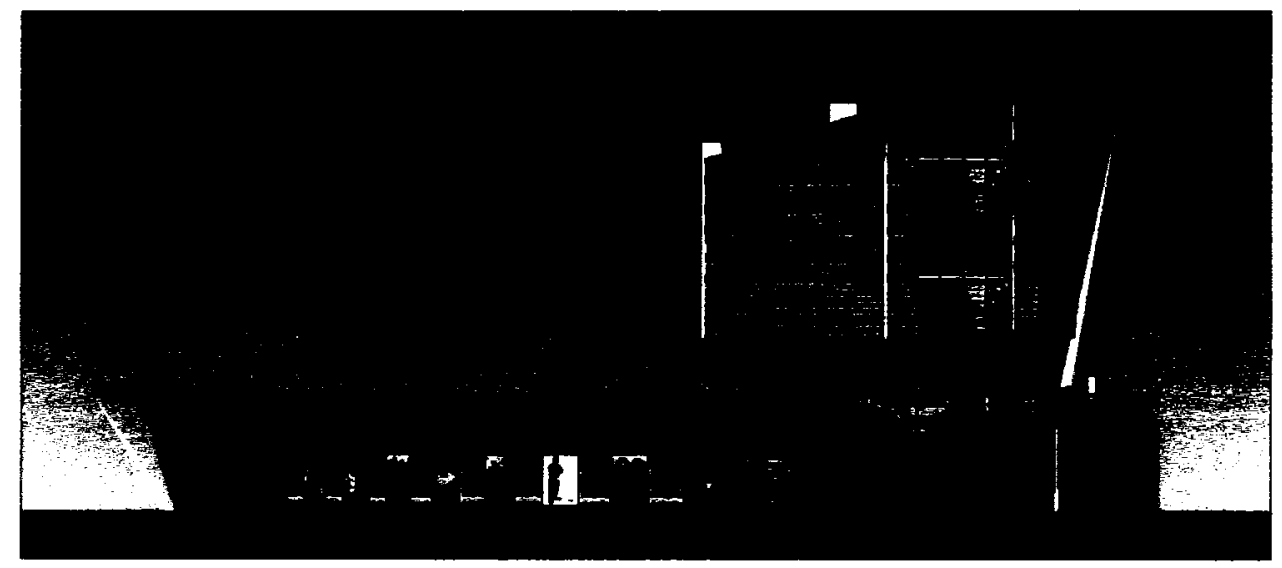

Figure 41. Digital Architectural Model: Left Elevation

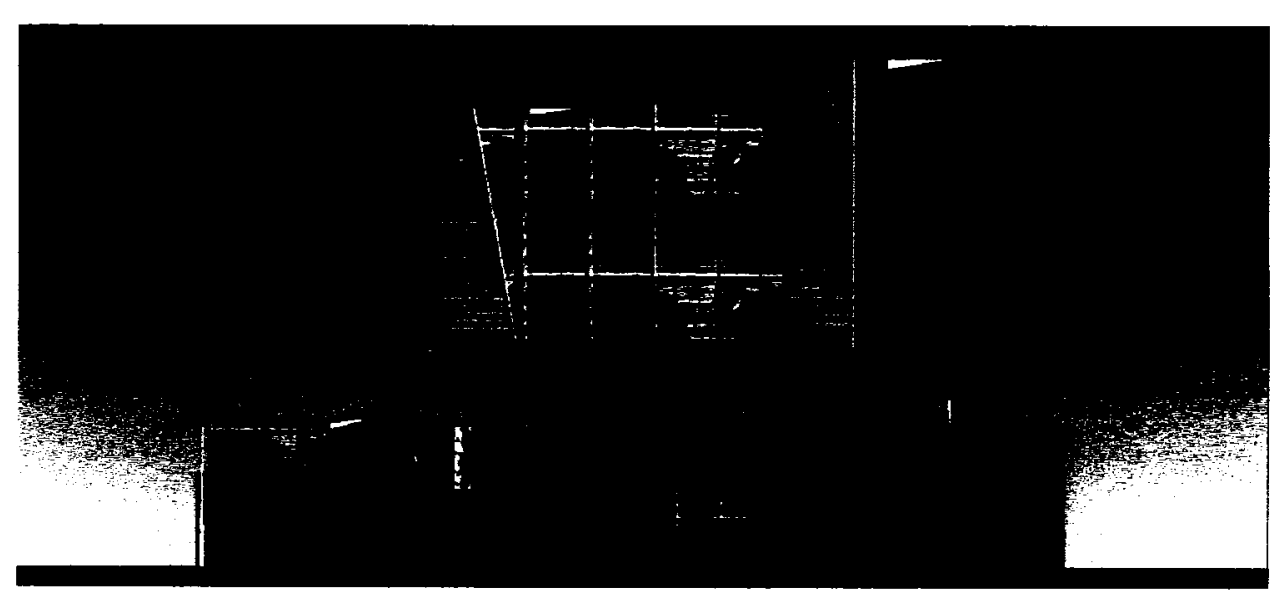

Figure 42. Digital Architectural Model: Rear Elevation

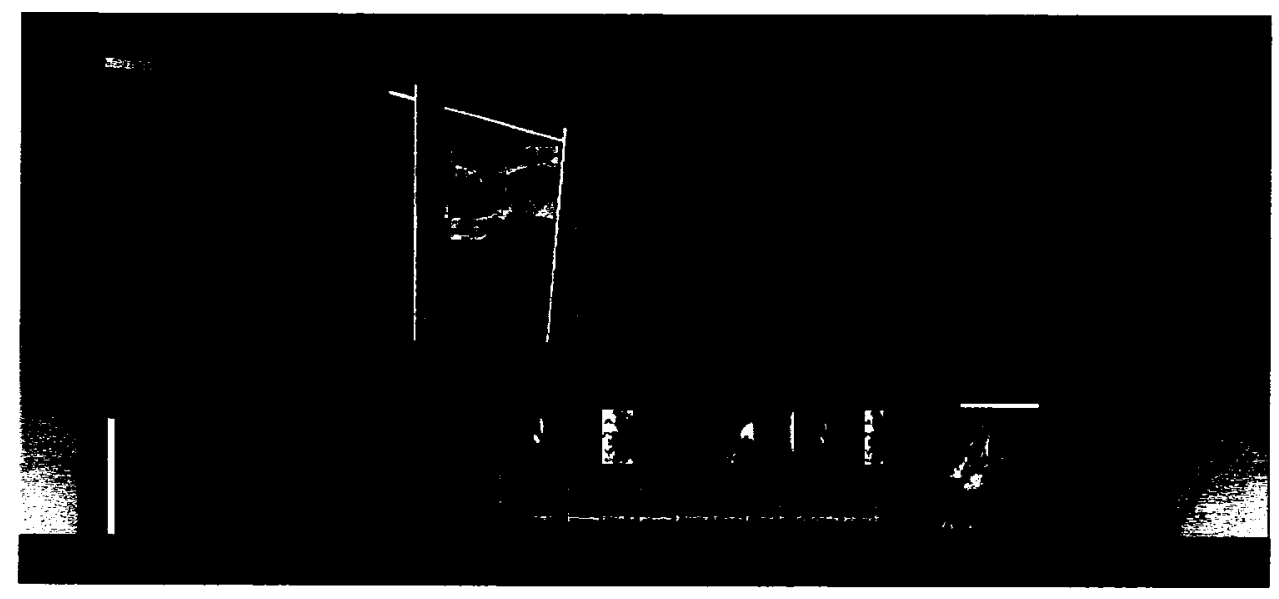

Figure 43. Digital Architectural Model: Right Elevation 


\section{Bibliography}

Barrie, Andrew. "Media Architecture $<>$ Architectural Media". Artspace Future Magazine. 18 June 2006. $<w w w . a r t s p a c e . o r g . n z / s h o w s / l t o . h t m>$

Chung, D.H. "Expanding Notions of Space, Light and Movement". EGO Magazine. 18 July 2002. <www.egothemag.com/archives/2005/04/toyo_ito.htm>

Deleuze, Gilles. Cinema1: The Movement Image. Trans. Hugh Tomlinson and Barbara Habberjam. Minneapolis: University of Minnesota Press, 1986.

"Blur Building." DesignBoom Magazine. 25 June 2006. $<w w w$.designboom.com/eng/funclub/dillerscofidio.html>

Diller, Elizabeth \& Ricardo Scofidio. "Blur Building". 12 August 2006.

<www.arcspace.com/architects/DillerScofidio/blurbuilding >

---. "Diller \& Scofidio: The Blur Building". 15 August 2006. $<w w w$.designboom.com/eng/funclub/dillerscofidio.html>

Hadid, Zaha. "Rosenthal Center for Contemporary Art". 04 February $2006<$ http://www.zaha-hadid.com/>

--- Contemporary Arts Center Page, 2003. ArcSpace Online Magazine. 15 June 2006. <http://www.arcspace.com/architects/hadid/contemporary_ar ts_center/contemporary_arts_center_index.htm>

Trans-Port Pavilion. Hipercroquis Online Magazine. 20 Oct. 2006. $<$ http://hipercroquis. wordpress.com/2006/10/05/trans-port2001-kas-oosterhuis/>

Headley, Robert. Motion Picture Exhibition in Washington, DC: An Illustrated History of Partors, Palaces and Multiplexes in the Metropolitan Area, 1894 - 1997. Jefferson, North Carolina \& London: McFarland \& Company Inc., 1999. 
Hofer \& Weber. "Lentos Museum of Modem Art Linz". Home

Page. 25 July 2006. <http://www.lentos.at/en/152_151.asp>

Ito, Toyo, Albert Ferre \& Tomoko Sakamoto. Toyo Ito: Sendai Mediatheque. Spain: Actar, 2002.

---. "Sendai Mediatheque". Home Page. 30 September 2006. $<$ http://www.smt.city.sendai.jp/en/>

Jun, Tanaka and Tajima Noriyuki. "Cyberspace and the City/Architecture/The Body". Intercommunication, No.24, Spring, 1998. 15 July 2006.

< http://www.ntticc.or.jp/pub/ic_mag/ic024/074-083e.pdf>

Kari, Jormakka. Flying Dutchmen: Motion in Architecture. Basel: Birkhauser, 2002.

Lentos Museum Home Page. 15 July 2006.

$<$ http://www.lentos.at/en/index.asp?nr=2>

Liu, Alan. "Transcendental Data: Toward a Cultural History and Aesthetics of the New Encoded Discourse." Critical Inquiry. 20 July 2006.

$<$ http://criticalinquiry.uchicago.edu/features/artsstatements/ar ts.liu.htm>

Lynn, Greg. Animate Form. New York, N.Y: Princeton Architectural Press, 1997.

Manovich, Lev. The Language of New Media . Cambridge, Mass.: MIT Press, 2001.

---. Behind the Scene: Russian New Media. 15 January 2006. $<$ www.ctheory.net/articles.aspx?id=93>

---. Understanding Meta Media. 15 January 2006. $<w w w . c t h e o r y . n e t / a r t i c l e s . a s p x ? i d=493>$

--. The Poetics of Augmented Space: Leaming from Prada. 9 June 2006.

<http://www.manovich.net/DOCS/augmented_space.doc> 
Markussen, Thomas \& Thomas Birch. "Transforming Digital Architecture from Virtual to Neuro: An Interview with Brian Massumi". IntelligentAgent Magazine. 15 Sept. 2006. $<$ http://www.intelligentagent.com/archive/Nol5_No2_massum i_markussen+birch.htm>

Mattelart, Armand. Advertising International. The Privatization of Public Space. London: Routledge, 1991.

McLuhan, Marshall. Understanding Media: The Extensions of Man. New York: McGraw-Hill, 1964.

-.- The Medium is the Massage: An Inventory of Effects. New York: Bantam Books, 1967.

McLuhan, Marshall and Bruce R. Powers. The Global Village: Transformations in World Life and Media in the 21st Century. New York: Oxford University Press, 1989.

McLuhan, Marshall and Eric McLuhan. Laws of Media : The New Science. Toronto : University of Toronto Press, 1988.

McPhee, Christina. Net Baroque. 20 January 2006 $<w w w . c t h e o r y . n e t / a r t i c l e s . a s p x ? i d=399>$

Novak, Marcos. Transmitting Architecture: The Transphysical City. 12 February 2006. <www.ctheory.net/articles.aspx?id=76>

Oosterhuis, Kas and Ole Bouman. Kas Oosterhuis: Programmable Architecture. Milano: L'Arcaedizioni, 2002.

Port Authority Bus Terminal. Basilisk Joumal Online. 15 July 2006. <http://www.basilisk.com/P/portauthority_561.html>

RealSpace in QuickTimes: EXPO. Netherlands Architecture Institute Online. 05 June 2006.

$<$ http://www.nai.nl/www_riq/expo_images.html> 
Scofidio, Ricardo. Home Page. Cooper Union School of Architecture. 20 July 2006.

<www.cooper.edu/architecture/faculty/scofidio/scofidio04.html>

Sendai Mediatheque: Galinsky Online. 01 June 2006.

$<w w w . g a l i n s k y . c o m / b u l d n g s / s e n d a i m e d i a t h e q u e / i n d e x . h t m>$

Slaatta, Tore. "Urban Screens: Towards the convergence of Architecture and Audiovisual Media". First Monday, Special Issue \#4: Urban Screens: Discovering the Potential of Outdoor Screens for Urban Society. 15 April 2006 <http://www.firstmonday.org/issues/special11_2/slaatta/\#aut hor>

Spuybroek, Lars, Brian Massumi, et al. Machining Architecture. London: Thames \& Hudson, 2004.

--. Hypersurface Architecture II. London: Thames \& Hudson, 2000

Stalder, Felix. "From Figure / Ground to Actor-Networks: McLuhan and Latour". Paper given at the Many Dimensions: The Extensions of Marshall McLuhan Conference, Toronto, 2325 October 1998.

Struppek, Mirjam. "The Social Potential of Urban Screens". Screens and the Social Landscape. Sage Publications, Volume 5, No.2, pp 173-188, 2006

---. "Urban Screens: Impressum". 18 August 2006 <http://www.urbanscreens.org>

Van Berkel, Ben \& Caroline Bos. "RealSpace in QuickTimes Expo". 12 February 2006.

<http://www.nai.nl/www_riq/RiQ_expo.html>

Virilio, Paul. The Vision Machine. Bloomington : Indiana University Press, 1994.

---. Lost Dimension. New York: Semiotext(e), 1994. 


\section{APPENDIX 1}

\section{The History of Adams Morgan and the Site at Eighteenth Street and Columbia Road at Adams Morgan, Washington, D.C.}

\section{The Neighborhood:}

Adams Morgan ${ }^{68}$, a historical neighborhood of Washington D.C., formerly called simply as Eighteenth Street and Columbia Road (referring simply to its major crossroads), has a history as a great place for shopping, dining, live music, art and nightlife ${ }^{69}$. The breezy hiltops in this area attracted Native Americans and Colonial settlers. Adams Morgan is the legacy of elite colonial families, Jewish merchants, liberal activists, revolutionaries, African American government clerks, transportation planners and entrepreneurs from Africa, Central and South America.

From the 1890's until the 1930's, Eighteenth Street and Columbia Road was known for its gentility, its furriers and caterers. A number of foreign embassies of Spanish speaking governments occupied

\footnotetext{
${ }^{68}$ From: Zapata, Celestino \& Josh Gibson. Adams Morgan: Then and Now. San Francisco: Arcadia Publishing, 2006.

${ }^{69}$ Please refer to Accompanying Material "History-Site.ppt" for a visual presentation of the history of Adams Morgan and the site and theatres at $18^{\text {th }} \mathrm{St}$ and Columbia Road NW, Washington D.C.
} 
mansions in this area, and their diplomats and domestic help began settling in the area as early as the 1910's. Adams Morgan is named for two once-segregated schools i.e., John Quincy Adams School serving white students and the Thomas $\mathrm{P}$ Morgan School serving black students. This area is remembered or the biracial cooperation of their principals and others to improve the community.

The identity of Eighteenth Street has continued to change over time from an initial residential street to shops, non-profit offices and art spaces. The lively scene on Eighteenth Street began with an arts movement in the 1950's. Musicians, dancers and artists found the centrally located Eighteenth Street attractive as declining rents made it affordable. Starting in the 1980's and continuing till today, while the street retains many vibrant retailers, today Eighteenth Street is dominated by restaurants, bars, and nightclubs. Adams Morgan remains a center of liberal political thought, and a home to protest planners and protests. Columbia Road was once a key festival and parade center for the District of Columbia, hosting the Adams Morgan Day Festival and the City's Latino Festival. The Adams Morgan Day Cultural Street Festival, first held in 1978, is a nationally known celebration of international foods, gifts, arts, 
jewelry, specialty products, street theater and music. This festival celebrates the creativity and diversity of this multi-ethnic and vibrant neighborhood of Washington D.C. (Americans, Latinos and Africans). It is presently staged on $18^{\text {th }}$ Street with its main stage located at the intersection of Eighteenth Street and Columbia Road.

\section{Site History:}

The site selected is the southwest corner of Eighteenth Street and Columbia Road NW in Adams Morgan, Washington DC. An empty open parcel of land up to 1915 , this site was former home to the Knickerbocker Theatre and Ambassador Theatres and site of a tragic roof collapse that killed nearly 100 people. Between its life as a music hall and movie theatre, and its current use as a bank and farmers market, the south west corner of Eighteenth Street and Columbia Road was planned to become a British Petroleum Gas Station. The idea did not go over well with residents and some of the first bilingual protests in Washington by neighborhood activists took place to save this site ${ }^{70}$.

${ }^{70}$ From: . Zapato, Celestino \& Josh Gibson. Adams Morgan: Then and Now. 2006. 85,94 
Knickerbocker Theatre $(1917-1922)^{71}:$ This theatre was designed by Washington architect Reginald Geare to seat 1700 patrons under the direction of Harry Crandall, a wealthy Washingtonian and owner of a chain of local movie theatres. The theatre opened on 13 October 1917. It was developed on the narrow triangular lot of Eighteenth Street and Columbia Road. The frontage was 173 feet on Eighteenth Street and 150 feet on Columbia Road. On January 21 1922, after a heavy snowfall, the roof of the theatre collapsed killing nearly 100 people.

Ambassador Theatre $^{72}$ (1923-1960): Crandall commissioned Thomas Lamb, a New York architect to design the Ambassador Theatre in place of the Knickerbocker Theatre. The Ambassador opened on 20 September 1923. Because of the competition with television, the Ambassador was sold to developers in 1965 and closed as a movie theater the following year. A high-rise apartment building was planned in its place. In August 1967, the theatre was leased and turned into a psychedelic rock concert hall with sound and lights. In October 1967, anti-was activists Norman Mailer, Robert Lowell, Paul Goodman and others met in the Ambassador

\footnotetext{
${ }^{71}$ Goode, James M. Capital Losses. p. 218, 219

72 Headley, Robert. Motion Picture Exhibition in Washington DC. p. 279,280
} 
to launch the march on the Pentagon. A weak, last-ditch effort was made to save the theatre but it failed and the theatre was demolished in 1969.

Present Day Land Use: A branch of the Perpetual Federal Savings and Loan Company was created there in 1978-79. Today, the site houses a police station, a branch of the SunTrust bank, and an open plaza that hosts a weekend farmers market. Two bus stops connect this historic neighborhood at Eighteenth Street and Columbia Road with the historic African neighborhood of U Street. The main stage of the Adams Morgan Day Festival is built on Eighteenth Street adjacent to the site. ${ }^{73}$

\section{References:}

Goode, James M. Capital Losses: A Cultural History of Washington's Destroyed Buildings. Washington: Smithsonian Institution, 2003.

Zapata, Celestino \& Josh Gibson. Adams Morgan: Then \& Now. San Francisco: Arcadia Publishing, 2006.

\footnotetext{
${ }^{73}$ Please refer to Accompanying Material "PresentDay-Site.wmv" Video documenting present day uses of the site and cultural events that occur on the site throughout the year.
} 